\section{Opsins}

Proteins homologous to rhodopsin that comprise seven $\alpha$-helical transmembrane regions and covalently bind retinaldehyde (the chromophore, a vitamin A derivative). In addition to retinal opsins, which function as G-protein-coupled receptors, there are many nonvisual opsins, including molecules that might act as photoisomerases, using light to convert all-trans retinaldehyde to its 11 -cis isomer.

*Australian National University, Division of Neuroscience, The John Curtin School of Medical Research, Garran Road, The Australian National University, Canberra, Australian Capital Territory 2600, Australia.

${ }^{\ddagger}$ University of Queensland, School of Biomedical Sciences, Brisbane, Queensland 4072, Australia. $\S$ University of Pennsylvania, F.M. Kirby Center for Molecular Ophthalmology, StellarChance Building, Room 309B, Philadelphia, Pennsylvania 19104-6069, USA. Correspondence to T.D.L. e-mail: Trevor.Lamb@anu.edu.au doi:10.1038/nrn2283

\title{
Evolution of the vertebrate eye: opsins, photoreceptors, retina and eye cup
}

\author{
Trevor D. Lamb*, Shaun P. Collin ${ }^{\ddagger}$ and Edward N. Pugh, Jr ${ }^{\S}$
}

Abstract | Charles Darwin appreciated the conceptual difficulty in accepting that an organ as wonderful as the vertebrate eye could have evolved through natural selection. He reasoned that if appropriate gradations could be found that were useful to the animal and were inherited, then the apparent difficulty would be overcome. Here, we review a wide range of findings that capture glimpses of the gradations that appear to have occurred during eye evolution, and provide a scenario for the unseen steps that have led to the emergence of the vertebrate eye.

To suppose that the eye, with all its inimitable contrivances... could have been formed by natural selection, seems, I freely confess, absurd in the highest possible degree... Yet reason tells me, that if numerous gradations from a perfect and complex eye to one very imperfect and simple, each grade being useful to its possessor, can be shown to exist... and if any variation or modification in the organ be ever useful to an animal under changing conditions of life, then the difficulty of believing that a perfect and complex eye could be formed by natural selection, though insuperable by our imagination, can hardly be considered real ${ }^{1}$. Charles Darwin (1809-1882)

More than 600 million years ago (Mya), early organisms evolved photoreceptors that were capable of signalling light, and that presumably mediated phototaxis, predator evasion by shadow detection or vertical migration, and the entrainment of circadian rhythms. However, it was not until the Cambrian explosion, beginning around $540 \mathrm{Mya}$, that animal body plans began evolving very rapidly ${ }^{2-4}$ and image-forming eyes and visual systems emerged. The possession of advantageous capabilities or attributes, such as sight, rapid movement and armour, might have become crucial to survival, and might have led to an 'arms race' in the development of defensive and offensive mechanisms ${ }^{5}$. In the various phyla eyes evolved with diverse forms, but apparently based on certain common underlying features of patterning and development, as exemplified by genes such as PAX6 and RAX (also known as RX), which have critical roles during neurulation and brain regionalization. For accounts of the origin and interrelationship of eyes in different phyla, see REFS 6-10.
Here we concentrate on the origin of the vertebrate eye. We summarize results from disparate fields: the emergence of the vertebrate (camera-like) eye, the evolution of photoreceptors, the phylogeny of opsins, the development of the eye cup, and the development of the retina. We then endeavour to integrate these findings to develop a plausible and coherent sequence for vertebrate eye evolution. To begin with, we summarize current ideas regarding the origin of vertebrates and the timescale involved.

\section{The origin of vertebrates}

FIGURE 1 illustrates a view of the evolutionary origin of vertebrates, in which the branching and timings are based primarily on morphological data and on the fossil record ${ }^{2,11-18}$. Although alternative patterns of branching and widely disparate timings have been derived from estimates based on 'molecular clocks' (that is, on the assumption that gene mutations have occurred at a fixed rate, or at least at a rate that can be estimated), we have instead based our datings on classical approaches because of the difficulties that have recently been demonstrated in the assumptions that underlie molecular-clock estimates $^{18-21}$.

Primitive bilateral animals gave rise to protostomes (including most invertebrates) and deuterostomes (including our own line) approximately $580 \mathrm{Mya}$, although molecular-clock estimates suggest an even earlier separation. Subsequent progression in the deuterostome branch led to the emergence of chordates, which possessed a notochord (at least in the embryo) together with a dorsal nerve cord. Animals with a skull (craniates) emerged approximately 550-500 Mya. Of extant 
craniates, hagfish have the most basal body-plan. They possess neither jaws nor vertebrae and are therefore usually regarded not as vertebrates but rather as a sister group. The vertebrates comprise an early jawless (agnathan) division, of which the only living examples are lampreys, and a later jawed division, the gnathostomes, which includes fish and tetrapods.

Controversy has long surrounded the interrelationship between hagfish, lampreys and jawed vertebrates. BOX 1 summarizes current views, and in FIG. 1 we show hagfish diverging either before the divergence of lampreys or else after lampreys separated from the line that would become the jawed vertebrates.
Not only has extensive gene duplication occurred throughout the evolution of animals ${ }^{22}$, but in addition it is widely accepted that two rounds of whole-genome duplication occurred early in vertebrate evolution $^{23-29}$; most likely, one duplication occurred before the agnathans split from the vertebrate line and one occurred after (FIG. 1; for reviews, see REFS 30-32). It is also clear that the vertebrate organizer, which determines the body plan of developing embryos, arose in early chordates ${ }^{33-35}$. These genetic developments are likely to have been of crucial importance in early vertebrate evolution, but they are beyond the scope of this Review.

\section{Protostome}

An animal belonging to the protostome super-phylum, which is characterized by its members' embryonic development, in which the first opening (the blastopore) becomes the mouth (protostome is Greek for 'first mouth'). All protostomes are invertebrates.

\section{Deuterostome}

An animal belonging to the deuterostome super-phylum of the animal kingdom, which is characterized by its members' embryonic development, in which the first opening (the blastopore) becomes the anus (deuterostome is Greek for 'second mouth'). In addition to the chordate phylum (which includeds vertebrates), the other two main phyla are the echinoderm phylum and the hemichordate phylum.

\section{Chordate}

An animal belonging to the chordate phylum, which comprises vertebrates, tunicates and cephalochordates. These animals are characterized by the presence of a notochord, a dorsal-nerve cord and pharyngeal slits or pouches.

\section{Agnathan}

A jawless fish within the chordate phylum (agnatha is Greek for 'no jaw'). The two extant groups are hagfish and lampreys.

\section{Gnathostome}

The jawed vertebrates (gnathostome is Greek for "jaw mouth'), comprising fish and tetrapods (including birds and mammals).

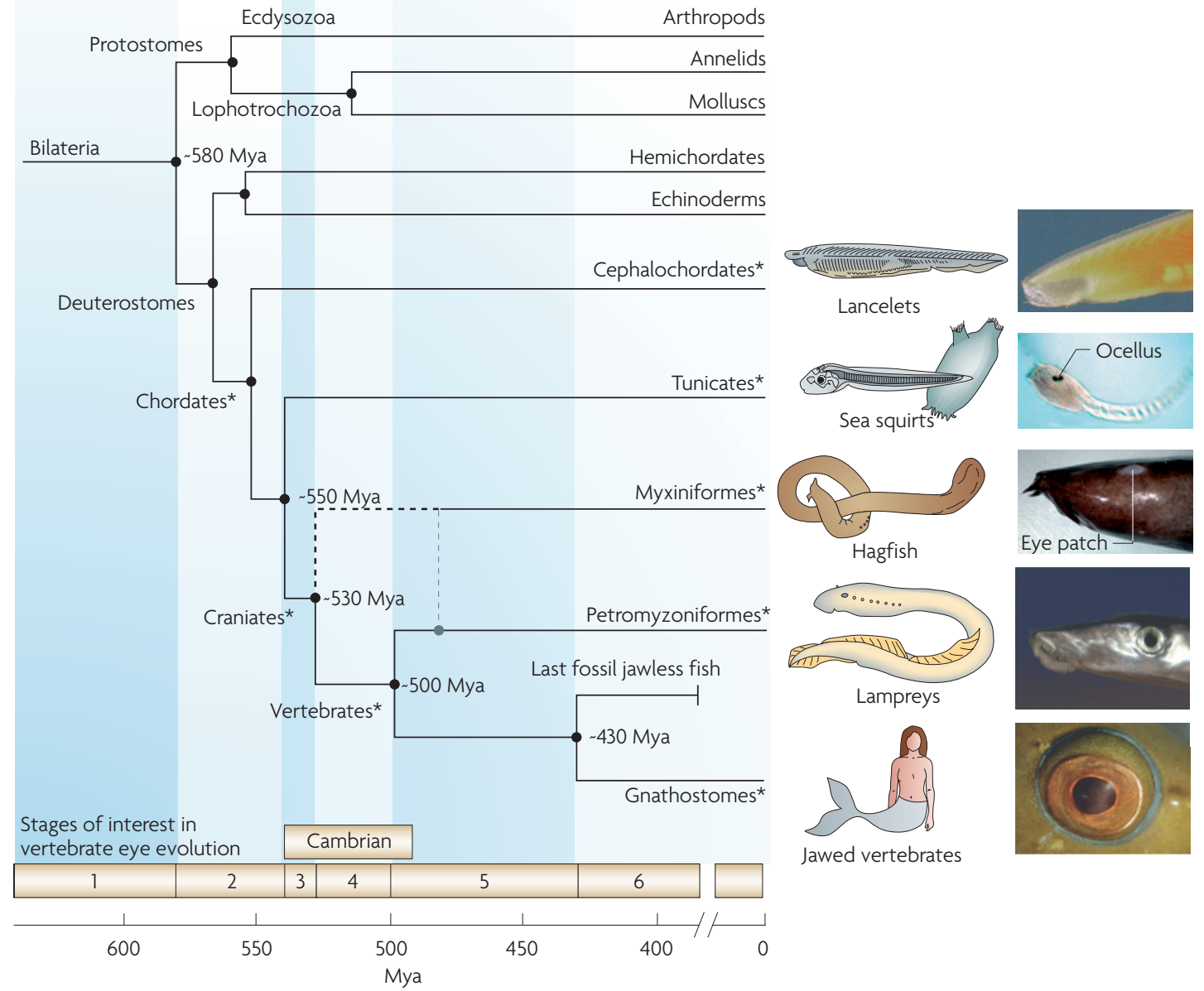

Figure 1 The origin of vertebrates. The evolution of jawed vertebrates is illustrated against an approximate time-scale of millions of years ago (Mya). The taxa considered in this Review are indicated with an asterisk and are accompanied by schematics and diagrams of the 'eye' region. The earliest chordates, represented by extant cephalochordates and tunicates, are thought to have appeared around 550 Mya. Jawless craniates (agnathans) were present in the early Cambrian, by 525 Mya, and a time of 530 Mya has been indicated for their presumed first appearance. As elaborated on in BOX 1, there is considerable controversy as to whether myxiniformes (solely represented by extant hagfish) diverged before or after the separation of lampreys from jawed vertebrates (shown as dashed black and grey lines). Numerous lines of jawless fish evolved between 500 and 430 Mya ago, although none have survived to the present day. The first jawed vertebrate arose around 430 Mya, and this line is represented today by cartilagenous fish, bony fish and tetrapods. Six 'stages of interest' in vertebrate eye evolution correspond to the time intervals between the divergence of important surviving taxa. This diagram does not include the evolutionary changes that have occurred in the last 400 million years. The presented timeline is based primarily on evidence from the fossil record; see REFS 2,13,15,17,18,144,160-163. The schematics are modified, with permission, from REF. 11 @ (1996) Oxford University Press (lancelet, sea squirt, hagfish and lamprey) and REF. 164 @ (2004) Academic Press (jawed vertebrate). The eye images are reproduced, with permission, from the following references: lancelet, REF. 165 (C) BIODIDAC (1996) University of California Museum of Paleontology; sea squirt, REF. 63 @ (2006) Blackwell Publishing; hagfish, REF. 166 C (2006) Australian Museum. Lamprey and jawed vertebrate eye images are courtesy of G. Westhoff and S. P. Collin). 


\section{Box 1 | The phylogenetic relationship of hagfish, lampreys and jawed vertebrates}

Controversy has long surrounded the interrelationship between hagfish, lampreys and jawed vertebrates. One view is that hagfish are basal, having diverged before lampreys split from gnathostomes, whereas an alternative view is that hagfish have degenerated from a lamprey-like ancestor, with hagfish and lampreys forming an agnathan clade, the cyclostomes (round mouths) (FIG. 1). Here we list evidence and arguments that support each view, together with several unresolved issues.

\section{Support for cyclostome monophyly (i.e. hagfish and lampreys as a clade)}

- Molecular-genetic analysis of mitochondrial and nuclear genes has provided strong support for the notion that hagfish and lampreys are sister taxa ${ }^{56,135-139}$

\section{Support for a hagfish basal position}

- Morphological data on the body plans of extant cyclostomes and their fossil relatives suggest that the unique features of hagfish are plesiomorphic (ancestral), and that these animals approach the condition of the common ancestor of all craniates $^{11,15,16,140,141}$.

- The hagfish 'eye' and retina are very simple, and resemble the pineal organ of vertebrates (see main text). Furthermore, during lamprey metamorphosis, the eye develops from a simple hagfish-like form to a vertebrate-like adult form.

- Other examples of simplicity are: that the semicircular canals of the labyrinth number just one in hagfish, but two in lampreys and three in jawed vertebrates ${ }^{140}$, and that the hagfish heart is not innervated.

\section{Unresolved issues that bear on the interpretation}

- The observed variability of molecular-clock rates ${ }^{19-21}$ might have implications for the above molecular-genetic estimates.

- It is possible that the role of 'long-branch attractions' might have been underestimated in previous molecular phylogenies of hagfish.

Vertebrate organizer An evolutionarily conserved region of the developing vertebrate embryo that specifies the patterning of the embryonic axis.

Extraocular and intraocular muscles

In jawed vertebrates, extraocular muscles orientate the eyeball in its orbit, whereas intraocular muscles focus the lens and adjust the pupil. In lampreys, the extraocular muscles perform the focusing by changing the curvature of the cornea.

Bipolar cells

Retinal neurons that convey information from

photoreceptors to the output neurons, retinal ganglion cells.

Horizontal cells

Large retinal neurons that mediate lateral interactions at the outer plexiform layer by contacting both

photoreceptors and bipolar cells.

\section{Amacrine cells}

A diverse class of retinal

neurons that make synaptic

contacts at the inner plexiform

layer and are involved in a

number of different processing

functions involving bipolar cells and ganglion cells.

Ganglion cells

The output neurons of the retina, the axons of which form the optic nerve and transmit information to the visua centres of the brain.

- Interpretation of the molecular-genetic differences will be greatly assisted once the entire genome of a hagfish is available. In the meantime, the identification of hagfish opsin genes might resolve the phylogenetic positioning.

- Extant hagfish display the vertebrate characteristic of delaminating neural-crest-like cells ${ }^{142}$, but this does not distinguish whether hagfish are basal or a sister group of lampreys.

- There is insufficient evidence to determine whether the hagfish eye has degenerated from a lamprey-like ancestor or is basal.

- Degeneration implies that the loss of vision was advantageous to the animals, which were presumably exposed to light throughout their evolution. The daytime intensity of light available to hagfish is sufficient for vision in other deep-sea species $^{143}$.

- There is as-yet no report of a fossil agnathan that possessed a lens ${ }^{144}$. If an ancestor of hagfish did possess a lens, degeneracy would be supported.

- During early development the hagfish appears to exhibit a 'lens placode', but the ancestral function of this structure might have been to prevent pigmentation of the overlying skin, rather than to induce lens formation ${ }^{145}$.

- If a primordial image-forming eye existed in ancestral hagfish, with a lens and a three-layered retina, and which sent its output to the thalamus, then this eye appears to have reverted to a lensless, two-layered retina connected to the region of the brain that regulates circadian rhythm.

\section{Our view}

On balance, and in the face of recent interpretations of the molecular evidence, we favour the view that hagfish are basal. In the words of Janvier ${ }^{141}$ (see also REF. 135): "All I can say is that, if cyclostomes are a clade, either hagfishes are the most extraordinary example of reversion among vertebrates, or lampreys and gnathostomes are the most extraordinary example of evolutionary convergence."

Whatever the phylogenetic relationship between hagfish and lampreys turns out to be, it is very likely that improved knowledge of the eyes and photoreceptors of these species will help to refine our understanding of the origin of the vertebrate eye.

\section{When did the 'vertebrate eye' emerge?}

The eye of the adult lamprey is remarkably similar to our own, and it possesses numerous features (including the expression of opsin genes) that are very similar to those of the eyes of jawed vertebrates. The lamprey's camera-like eye has a lens, an iris and extra-ocular muscles (five of them, unlike the eyes of jawed vertebrates, which have six), although it lacks intra-ocular muscles ${ }^{11}$. Its retina also has a structure very similar to that of the retinas of other vertebrates, with three nuclear layers comprised of the cell bodies of photoreceptors and bipolar, horizontal, amacrine and ganglion cells $s^{36,37}$. The southern hemisphere lamprey, Geotria australis, possesses five morphological classes of retinal photoreceptor and five classes of opsin, each of which is closely related to the opsins of jawed vertebrates $^{38}$ (see below).

Given these similarities, we reach the inescapable conclusion that the last common ancestor of jawless and jawed vertebrates already possessed an eye that was comparable to that of extant lampreys and gnathostomes. Accordingly, a vertebrate camera-like eye must have been present by the time that lampreys and gnathostomes diverged (by the end of stage 4; see FIG. 1), around 500 Mya. 


\section{Earlier chordate 'eyes'? Hagfish and others}

Might an even more ancient vertebrate-type eye remain in existence? Possibly so - in hagfish, which, as mentioned above, are a group of primitive, jawless, eel-shaped marine chordates.

Pineal organ

Also known as the epiphysis. A protrusion from the dorsal surface of the diencephalon that is involved in the secretion of melatonin and the regulation of circadian rhythms. In non-mammalian vertebrates the pineal contains photoreceptors that are homologous to those in the retina of higher species, but in mammals the corresponding cells do not have outer segments and are not intrinsically light-sensitive.

Amphioxus

Also known as lancelets.

Members of the

cephalochordate sub-phylum, and perhaps the most basal members of the chordates.

\section{Ciona intestinalis}

A well studied member of the ascidian class

Ascidia

Commonly known as seasquirts. A class within the tunicate sub-phylum. The larval form is tadpole-shaped and possesses a simple nervous system

Phototransduction In both ciliary and rhabdomeric photoreceptors,

phototransduction is mediated by a photoactivated opsin (a

G-protein-coupled receptor] activating a $\mathrm{G}$ protein. In

vertebrate photoreceptors the $\mathrm{G}$ protein activates a

phosphodiesterase that hydrolyses cyclic GMP in the cytoplasm, leading to the closure of ion channels in the plasma membrane. Shutoff is mediated by

phosphorylation of the opsin followed by the binding of a capping protein, arrestin.

Retinal pigment epithelium The pigmented monolayer of cells intervening between the retina and the choroidal circulation, that serves multiple functions in recycling retinoid, phagocytosing the apical tips of the outer segments, absorbing light that passes through the retina, etc. In hagfish the retinal epithelium is not pigmented.
The hagfish eye. Hagfish eyes ${ }^{39}$ are small, conical, completely lacking in any sign of a lens, an iris, a cornea or intra- or extraocular muscles, and buried beneath unpigmented translucent skin $^{39,40}$. The retina contains only two main nuclear layers, with no obvious bipolar or amacrine cells, and the photoreceptors connect directly to the output neurons (ganglion cells) ${ }^{36,41-43}$. In hagfish, these ganglion cells project predominantly to the hypothalamus ${ }^{44,45}$, just as their likely homologues, the melanopsin-containing retinal ganglion cells, do in mammals ${ }^{46}$. Hagfish photoreceptors have a simple structure $^{36,39,42,43}$ (FIC. 2), with rather poorly organized outer-segment membranes. In each of these respects the hagfish eye resembles the pineal organ of non-mammalian vertebrates $^{47,48}$, with the exception that the hagfish eye is arranged bilaterally. Behaviourally, the hagfish seems to be almost blind, and its weak response to light is unaffected by removal of its eyes ${ }^{49}$. Thus, the hagfish 'eye' seems not to subserve vision; instead, it seems more likely to function as a circadian organ, similar to the gnathostome pineal complex (which hagfish lack).

The larval lamprey eye. The developmental changes that occur in the eyes of lampreys provide support for the notion that the ancestors of these animals succeeded those of hagfish in evolution. Lampreys have a larval form (the ammocoete) that develops slowly, over a period of 5 years or more, before metamorphosing into the adult ${ }^{50}$. The ammocoete is effectively blind, and its eyes are similar to those of the hagfish: they are small, they are buried beneath skin and they possess a relatively undifferentiated retina. Although the ammocoete retina contains a narrow central region $(\sim 50 \mu \mathrm{m}$ wide, adjacent to the optic nerve) that is differentiated into the conventional three layers of vertebrate retinal neurons, the bulk of the larval retina remains undifferentiated, with a thick neuroblastic layer ${ }^{50-53}$. Over a period of years, a slow process of neural differentiation occurs, in the following sequence: ganglion cells, amacrine and horizontal cells, photoreceptors and finally bipolar cells ${ }^{51,52}$. This is broadly the same order as that in which the jawed-vertebrate retina differentiates $^{54}$ (see below), although the ammocoete retina differentiates much more slowly. At metamorphosis, the lamprey eye grows considerably in size, the retina differentiates fully, the lens develops, the cornea splits into scleral and dermal layers ${ }^{55}$ (allowing the eye to move with respect to the epidermis, as in jawed fish), extraocular muscles develop and the eye erupts at the surface to form a vertebrate-style visual organ.

This developmental progression is explained most parsimoniously if we assume that lampreys inherited their eyes from an ancestor that they had in common with hagfish, and that this hagfish-like larval eye is present in the larva but transforms to a vertebrate-like eye in the adult, and thus that lampreys arose from a hagfish-like ancestor. Alternatively, it is possible that extant hagfish correspond to an arrested form of lamprey development, and that hagfish are effectively a neotenous sister group to lampreys (BOX 1).

The primordial photosensory system of protochordates. Although the hagfish eye is phylogenetically the earliest organ to exhibit a physical similarity to the vertebrate eye, clues to the molecular origin of the eye are retained in other extant organisms that diverged from the vertebrate line even earlier, such as amphioxus and Ciona intestinalis. Until recently it was thought that cephalochordates were the closest living relatives of vertebrates, with ascidia having diverged earlier; however, recent evidence has reversed this order, as illustrated in FIG. 1 (REF. 56). The tadpole-like larvae of sea-squirts (ascidians) such as C. intestinalis have a simple photosensory organ called an ocellus (FIG. 1). This ocellus contains a handful of ciliary photoreceptors (described below) surrounded by a single large pigment-containing cell ${ }^{57-59}$.

Many aspects of phototransduction and eye (or ocellus) development appear to be homologous between ascidians and vertebrates. Thus, the light-response of ascidian photoreceptors is hyperpolarizing ${ }^{60}$, as for vertebrates. Phototransduction in C. intestinalis uses a single opsin, $\mathrm{Ci}-\mathrm{Opsin} 1$, which diverged from an ancestral ciliary opsin before the appearance of separate classes of vertebrate retinal and pineal opsins ${ }^{61}$, and a single class of arrestin that has close homology to cone arrestin ${ }^{62}$. In addition, the development of the ocellus requires the transcription factor $\mathrm{Ci}-\mathrm{Rx}^{63}$, which is homologous to RAX, the highly-conserved transcription factor that is involved in vertebrate eye development ${ }^{63}$. Furthermore, the expression profile of transcription factors in the pigment cell of the ocellus resembles that in vertebrate retinal pigment epithelial (RPE) cells ${ }^{64}$. Finally, the ocellus contains homologues of three vertebrate proteins that are involved in the retinoid cycle of vision: RPE65, CRALBP and retinal G-protein-coupled receptor (RGR) opsin ${ }^{65}$. These and further observations strongly support the notion that a common ancestor of sea-squirts and vertebrates possessed a photoreceptive organ that contained many of the building blocks that are fundamental to light signalling in our own eyes.

Cephalochordates. The cephalochordate amphioxus has both ciliary and rhabdomeric photoreceptors, located in four separate non-imaging structures: the frontal 'eye' and lamellar body (ciliary), and the Joseph cells and dorsal ocelli (rhabdomeric) ${ }^{66,67}$. Amphioxus has six distinct opsins ${ }^{68}$, with the melanopsin-like opsin driving a $\mathrm{G}_{\mathrm{q}}$-based phototransduction mechanism ${ }^{69}$, and the encephalopsin and peropsin homologues thought to drive $\mathrm{G}_{\mathrm{t}}$ - and $\mathrm{G}_{\mathrm{o}}$-coupled mechanisms, respectively ${ }^{68}$. Like $C$. intestinalis, amphioxus has been the subject of extensive evolution-development studies that include the mapping of transcription factors $^{70,71}$. One interesting possibility (see below) is that the rhabdomeric photoreceptors in an ancestral chordate similar to amphioxus might have received synaptic input from ciliary photoreceptors and subsequently evolved in craniates to become retinal projection neurons ${ }^{72}$. 


\section{Origin of vertebrate photoreceptors}

The photoreceptor cells of animals can be classified into two types: rhabdomeric or ciliary. One of the main differences between these types relates to the topology of the large area of membrane in which the photopigment (opsin) is incorporated: rhabdomeric photoreceptors use apical microvilli, whereas ciliary photoreceptors extend membranes from a modified cilium (characterized by a 9+0 microtubule organization) (see schematic insets in FIG. 3). Rhabdomeric photoreceptors use a $G_{q}-$ or $\mathrm{G}_{\mathrm{o}}$-mediated G-protein-coupled signalling cascade that elicits a depolarizing response to light, whereas ciliary photoreceptors generally use a $\mathrm{G}_{\mathrm{t}}$-mediated G-protein cascade that elicits a hyperpolarizing response to light; however, in both classes of photoreceptor the graded voltage signals are transmitted across a synapse that is electrotonically close to the soma. The visual pigments of the two types of photoreceptor fall into two corresponding clades of rhabdomeric and ciliary opsins ${ }^{8,73}$, as discussed below.

Until recently, it was widely thought that rhabdomeric photoreceptors are present exclusively in protostomes (comprising most invertebrates), whereas ciliary photoreceptors are present exclusively in deuterostomes (including chordates). However, it is now clear that both types can coexist in a variety of organisms, including the chordate amphioxus ${ }^{67}$, the polychaete worm Platynereis ${ }^{72}$, the scallop ${ }^{74}$ and possibly insects ${ }^{75}$ - that is, in chordates, annelids, molluscs and arthropods, respectively (FIG. 1).

In analysing the phylogenetic relationships between opsins, and between the transcription factors that specify eye development, Arendt and colleagues concluded that the bilateral common ancestor of protostomes and deuterostomes (see stage 1 of FIG. 1) possessed both rhabdomeric and ciliary photoreceptors ${ }^{8,9,72}$. Furthermore, they proposed that vertebrate retinal ganglion cells are sister cells of rhabdomeric photoreceptors, on the basis of the close homology in the transcription factors used by the two classes of cell and the finding that melanopsin (which is contained in a sub-class of light-sensitive retinal ganglion cells) is a member of the rhabdomeric class of opsins ${ }^{9,72,76}$. Hence, it is entirely plausible to view our own retinal ganglion cells as rhabdomeric photoreceptors that have lost their rhabdomeric membrane structure, retained their axon, their ancestral responses to neurogenic factors and, in some cases, their rhabdomeric opsin and G-protein signalling cascade, and that have evolved the ability to receive synaptic input from ciliary photoreceptors.

The evolution of ciliary photoreceptors. The morphology of ciliary photoreceptors is illustrated in FIG. 2 at several 'stages' of chordate evolution, from tunicates to mammals. A smooth transition of features from stage to stage is apparent, compatible with the sequential acquisition of these features in ancestral forms. The stages we have illustrated are: the ascidian larva ocellus $^{58,77}$, the hagfish eye $\mathrm{e}^{36,39-43}$, the lamprey pineal $\operatorname{organ}^{48,78,79}$, the lamprey retina ${ }^{36,80-85}$ and the jawedvertebrate retina.
In each case, the membrane that contains the photopigment extends from a cilium, and this region of the cell is denoted as the outer segment. In the ascidian larva (which reflects completion of stage 2), the membranes are organized approximately longitudinally with respect to the cell's axis, rather like the petals in a rosebud. In hagfish (which reflect the end of stage 3 ), the membranes radiate more laterally, from a central cilium. In pineal photoreceptors (of lampreys), the cilium occupies an offaxis position and the outer-segment membranes appear a little more evenly stacked than in hagfish. In the retinal photoreceptors of vertebrates (jawless and jawed, reflecting completion of stage 4 onwards), the membranes are neatly stacked and highly ordered and the connecting cilium is lateral - that is, it is at the edge of the conical or cylindrical outer segment.

The ascidian photoreceptor (which arose by the end of stage 2) differs from the photoreceptors that arose at stage 3 onwards in other ways as well. For example, the neck of the ascidian photoreceptor (corresponding roughly to the inner segment) is surrounded by a pigment-containing cell, which appears to extend microvilli that interdigitate with the membranes of the outer segment. Thus, the pigmented cell in the ascidian larva has its soma in the same layer as the photoreceptors, rather than in a layer (such as the RPE) that has folded over the photoreceptor layer. Light normally reaches the ascidian photoreceptor from the outer-segment side, and the pigment granules shield the outer segment from light arriving from the opposite direction, so that the ocellus is of the everted type, rather than being inverted, as in the vertebrate eye.

In hagfish photoreceptors, the presynaptic terminal contains a synaptic density surrounded by synaptic vesicles $^{36,43,86,}$ whereas vertebrate photoreceptors are generally reported to exhibit a clearly-developed ribbon synapse. However, it has been reported that the vertebrate 'ribbon synapse' can in fact contain both spherical and ribbon synaptic bodies ${ }^{87,88}$. In both the hagfish retina and the vertebrate pineal organ, synaptic output occurs directly onto projection neurons (ganglion cells). In the retina of both jawless and jawed vertebrates the output occurs onto interneurons (horizontal and bipolar cells).

It has been known for many years that the retina of northern hemisphere lamprey species possesses two classes of retinal photoreceptor, that have either long (cone-like) or short (rod-like) outer segments ${ }^{80}$. On the other hand, the southern hemisphere lamprey, Geotria australis, has been shown to possess five morphological classes of photoreceptor, all of which are cone-like ${ }^{85}$, together with five classes of opsin ${ }^{38}$. This correspondence suggests that each class of photoreceptor might express a single class of opsin ${ }^{89}$, although RNA in situ hybridization will be needed to confirm this. Most non-mammalian vertebrates possess four classes of cone opsin, together with rhodopsin, which is expressed in rods, whereas mammals have lost two of these classes: SWS2 and Rh2. The recent results from G. australis ${ }^{38}$ indicate that at least four classes of opsin (long-wave sensitive (LWS), shortwave sensitive 1 (SWS1), SWS2 and an Rh opsin) evolved before the separation of lampreys and gnathostomes - that is, by the end of stage 4, around 500 Mya. 


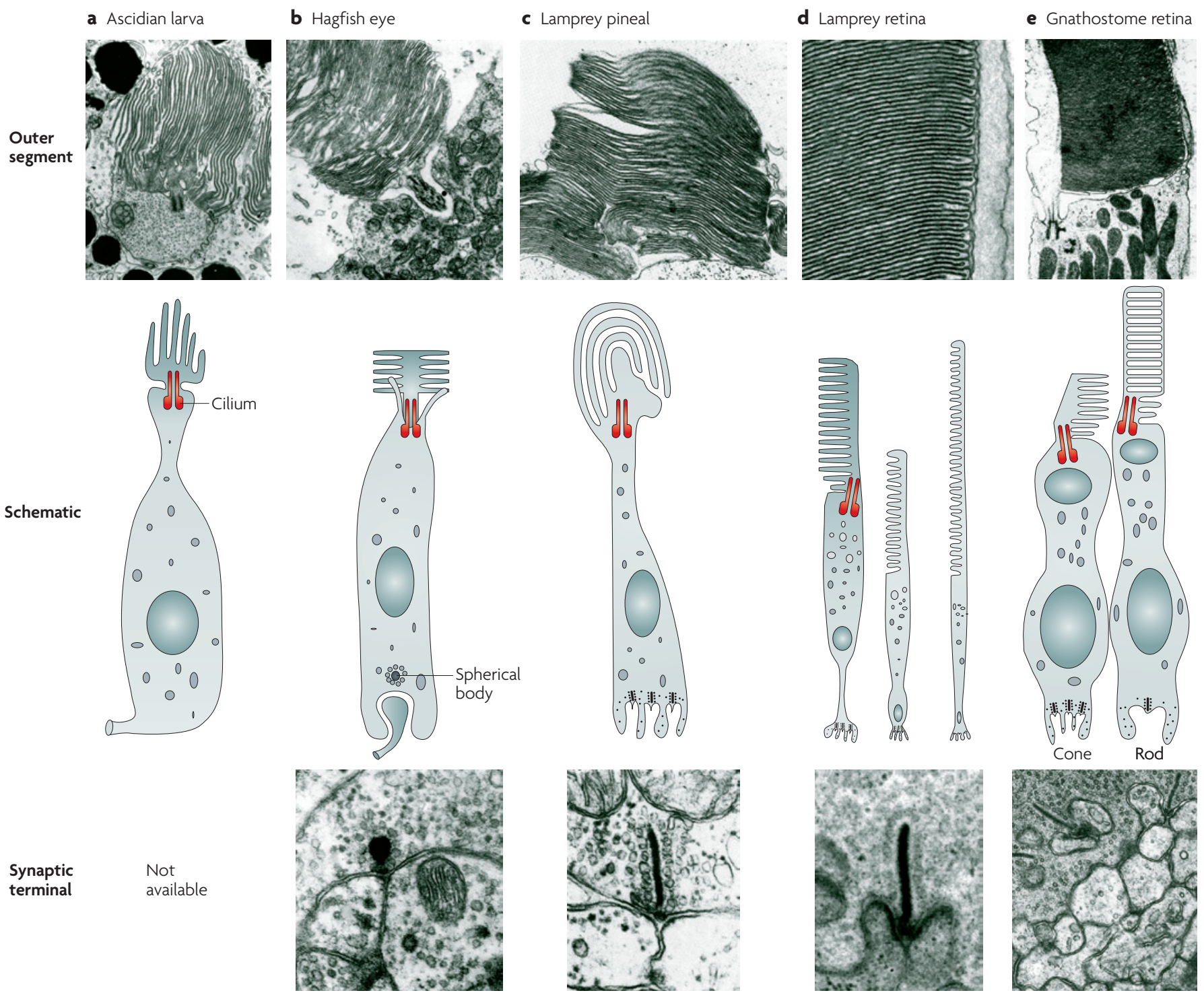

Figure 2 | The structure of ciliary photoreceptors at various stages of chordate/vertebrate evolution. The middle row shows schematic diagrams of the entire photoreceptor; the top and bottom rows show electron micrographs of the outer segment and the synaptic terminal, respectively. Note the gradual transition towards a highly organized laminar structure in the outer segment and the appearance of ribbons in the synaptic terminal. The schematics are modified with permission from, and the micrographs are reproduced with permission from, the following references: ascidian larva (schematic), REF. 58 (C) (1971) Springer Verlag; ascidian larva (outer segment), REF. 59 @ (1971) Springer Verlag; hagfish eye, REF. 43 (C) (1971) Springer Verlag; larval lamprey pineal, REF. 78 (C) (1981) American Physiological Society; adult lamprey retina, REF. 167 C (2006) Science Publishers; gnathostome retina (outer segment), REF. 168 (C (1980) Wiley-Liss; gnathostome retina (schematic), REF. 169 (C) (1997) Springer Verlag; gnathostome retina (synaptic terminal), REF. 170 C (1975) Rockerfeller University Press.

Together, these observations indicate a continuous transition in the characteristics of ciliary photoreceptors, over the time span represented by stages 1 to 6 .

\section{The evolution of vertebrate opsins}

In studying the evolution of photoreceptors, it will ultimately be important to obtain a comprehensive understanding of the evolution of all of the components of the phototransduction signalling cascade, as well as of all of the factors that determine cell morphology. Although information about the parallel evolution of the many proteins that are involved in phototransduction is rapidly emerging ${ }^{90,91}$, the greatest progress to date has been made in relation to the opsin photopigments, on which we now concentrate.

FIGURE 3 shows a phylogenetic tree of important visual and non-visual opsins ${ }^{92}$. Before the separation of protostomes and deuterostomes, a primordial opsin had divided into three main branches: a rhabdomeric branch, a 'photoisomerase' branch and a ciliary branch. In vertebrates, the first two branches have given rise to melanopsin, which is expressed in retinal ganglion cells, 

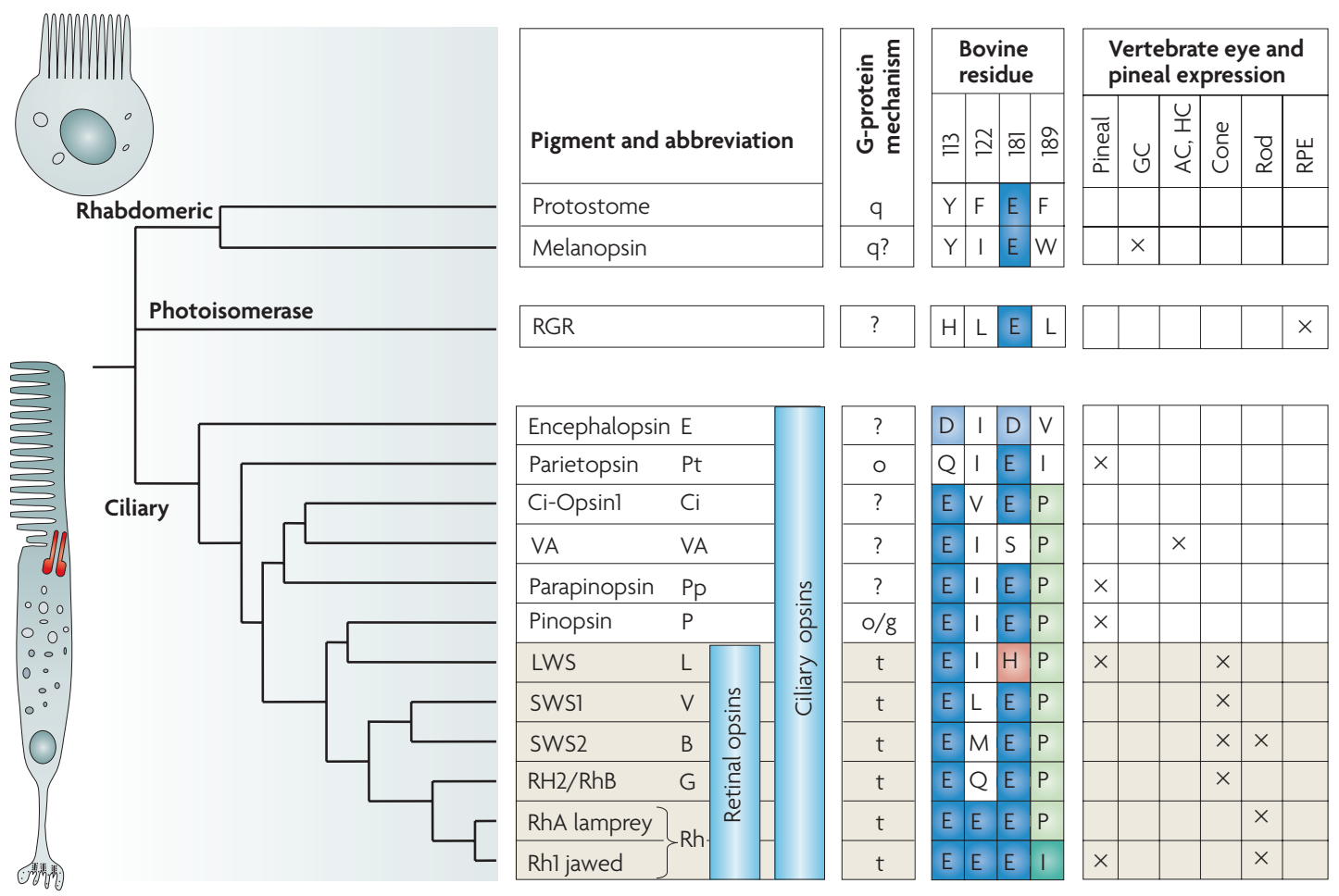

Figure 3 | The evolution of vertebrate opsins. On the left of the main figure is a dendrogram of the major opsin classes that are relevant to the evolution of the vertebrate eye. Before the separation of protostomes and deuterostomes, the primordial opsin had already diverged into three main classes: rhabdomeric opsins, which are characteristic of protostome rhabdomeric photoreceptors (see upper photoreceptor schematic) but are also found in melanopsincontaining vertebrate retinal ganglion cells; 'photoisomerase' opsins, such as retinal G-protein-coupled receptor (RGR) opsin and peropsin, which may in fact be G-protein-coupled receptors; and ciliary opsins (see lower photoreceptor schematic), which are characteristic of those photoreceptors in which the pigment-containing region is an expansion of the membrane of a cilium. Vertebrate retinal opsins are represented by the lowermost six rows in the diagram. The primordial retinal opsin of vertebrates diverged into long-wavelength sensitive (LWS) and short-wavelength-sensitive (SWS) branches, and then the latter split into several sub-groups: SWS1, SWS2 and Rh2/RhB, each of which is associated with cone-like photoreceptors. The Rh1 pigment of jawed vertebrates (bottom line) seems to represent the most recent development among these classes, and is expressed in vertebrate rod photoreceptors. A separate class of rod, the 'green rod' of non-mammalian vertebrates, uses the SWS2 pigment that is also present in the blue-sensitive cones of these species. On the right of the main figure are presumed classes of G-protein coupling mechanism, residues at four important locations (in the numbering system for bovine rhodopsin; blue and green shading highlights residue similarity; pink shading highlights a chloride-binding site), and the regional expression of the opsins in vertebrate tissues. AC, amacrine cell; GC, ganglion cell; HC, horizontal cell; RPE, retinal pigment epithelium; VA, vertebrate ancient. The dendrogram is a composite, based on data from REFS 73,92,93,101,108 and elsewhere. The schematic of the rhabdomeric photoreceptor is modified, with permission, from REF. 171 (c) (2001) Macmillan Publishers Ltd. The schematic of the ciliary photoreceptor is modified, with permission, from REF. 172 @ (2003) MIT Press.

\section{Schiff base}

A class of chemical bond that covalently links the retinaldehyde chromophore of visual pigments to the terminal amino group of a lysine residue in the opsin protein. and to RGR and peropsin, which are expressed in the RPE. The ciliary branch has given rise to many opsins, which are expressed in the pineal complex, in the retina and in deep-brain regions. The branching pattern of vertebrate retinal opsins that is shown in FIG. 3 was elucidated in 1992 by Shichida and colleagues, who deduced that all four classes of cone pigment were present before the evolution of the rod pigment, rhodopsin ${ }^{93}$.

Subsequent studies have shown how the roles of several key sites have altered during evolution ${ }^{94-97}$, and have defined the molecular characteristics of the different classes of op $\sin ^{98-105}$. In almost all visual pigments the overall length of conjugated single and double bonds in the retinaldehyde chromophore is increased by the use of a protonated Schiff base bond between the chromophore and a lysine residue in the opsin. This bond must be stabilized by a nearby negative ion. In the presumed ancestral opsin, the counter-ion (Glu) was located at residue 181 (where it remains in rhabdomeric and photoisomerase opsins), but in the ciliary photoreceptors of $C$. intestinalis and craniates, the site of the counter-ion has moved to residue 113 (REF. 95). A negative ion is nevertheless retained at residue 181 in all ciliary opsins (except vertebrate ancient (VA) opsin), and there is evidence that this site is crucial to light activation and that the ion acts as the counter-ion in the photoactivated metarhodopsin-I state ${ }^{106}$.

Although the LWS opsins do not have Glu181 (FIG. 3), they nevertheless retain a negative charge by using a chloride-binding site, His181/Lys184 (REF. 107), as the 
secondary counter-ion. Although this change has had the benefit of extending the spectral sensitivity of LWS opsins further into the long-wavelength region, it has done so at the cost of greatly decreasing the thermal stability of the molecule.

Two amino acid sites, 122 and 189, have been identified as being especially important in distinguishing rhodopsin from cone opsins ${ }^{94,97}$. The rhodopsin of jawed vertebrates has a Glu at site 122 and an Ile at site 189 , and site-directed mutagenesis has shown that these residues invest the molecule with a number of its rod-like properties: increased thermal stability, slowed decay of the photointermediates (the so-called metarhodopsins) and slowed regeneration of the pigment in darkness ${ }^{94,96,97}$.

Lamprey rhodopsin. Judging by the amino-acid residues at its site 122 and its site 189, lamprey 'rhodopsin' (RhA) is intermediate between rod and cone opsins ${ }^{96}$ : it has the rod-type Glu122 but the cone-type Pro189 (FIG. 3). As mentioned previously, the photoreceptors that this opsin is incorporated into have cone-like morphology ${ }^{85}$; furthermore, both the short and long types of photoreceptor in the northern hemisphere lamprey, Lampetra fluviatilis, display properties that are cone-like: neither saturates at high light intensities ${ }^{80}$. In addition, it has recently been found that the phototransduction cascade in the photoreceptors of the southern hemisphere lamprey, G. australis, appears to be driven by a single set of cone-like phototransduction genes ${ }^{108}$. Together, these results suggest that the features of 'true' rod transduction in jawed vertebrates, which permit the reliable detection of single photons of light, evolved after the separation of gnathostomes from lampreys.

\section{The development of the vertebrate eye cup} Embryonic development in relation to evolution. Early in the nineteenth century, Karl Ernst von Baer ${ }^{109}$ observed that organisms with widely different adult forms have embryos that closely resemble each other, and he suggested that the developmental stages through which the embryo passes might reflect the evolutionary history of the organism. Even though evolution selects from all stages of embryogenesis, the fundamental body plan that was established early in evolution does not often seem to be altered in a major way during embryogenesis; instead there appears to be a tendency for newly evolved features to be 'tacked-on' to later stages of embryogenesis. von Baer's ideas were subsequently expanded upon by Ernst Haeckel ${ }^{110}$, to produce what is widely regarded as the extreme and simplistic view that 'ontogeny recapitulates phylogeny'. Despite the controversy that was aroused by Haeckel, it nevertheless seems likely that a range of features in the development of the vertebrate eye reflect stages in its evolutionary history and, furthermore, that analysis of such apparently conserved features might permit the formulation of testable hypotheses about the morphogenetic mechanisms of the retina.

During vertebrate development the eyes arise as evaginations from the developing diencephalon (FIG. 4; animated online). Depressions called optic grooves form on each side of the rostral neural plate (FIG. 4b), and as the neural plate folds upwards and inwards (FIG. 4b,c), meeting and closing-over to form the neural tube, these growing regions balloon outwards (FIG. 4d) and are now termed optic vesicles. Contact between the expanding optic vesicle and the surface ectoderm (FIG. 4e), at a region termed the lens placode, induces changes in both tissues. The vesicle now invaginates to form the optic cup (FIG. 4f), while the ectoderm differentiates to form the lens pit and eventually the lens itself (FIG. 4g). Although it is sometimes suggested that invagination of the optic cup is a physical result of growth of the lens, this cannot be the case, because a normal eye cup and retina can develop in the absence of a lens, as in human congenital primary aphakia ${ }^{111}$. In our view, it seems plausible that a sequence broadly comparable to that described above might have occurred during the evolution of the vertebrate eye.

Recently a time-lapse imaging study of the developing zebrafish forebrain succeeded in tracking the cell migrations that occur very early in the development of the eye ${ }^{112}$. The animations that accompany this study provide impressive visualizations of the coordinated cellular migrations that are involved in eye formation.

One important aspect of the invagination of the optic cup is that it brings the future retina into contact with the future RPE (FIG. 4f). Thus, the pigmented RPE cells, which isomerize the chromophore retinal to its 11-cis form and synthesize melanin, which helps to attenuate unwanted light, now lie in the inverted position - 'behind' the photoreceptor cells (in terms of the path of incident light). Furthermore, they no longer occupy space in the photoreceptor layer, so that more of the light can be captured. These factors might help to explain the inverted nature of the vertebrate retina.

The folded arrangement of the vertebrate retina and RPE provides an evolutionary explanation for the occurrence of the choroid fissure, as proposed more than a century ago ${ }^{113}$. Early in evolution, before the optic cup invaginated, the axons from retinal ganglion cells would simply have run over the surface of the structure. Hence, one can view the optic nerve as having acted rather like a rope in linking the retina to higher centres: the developing eye cup has simply wrapped around this 'rope', and the developing axons have thereby not needed to penetrate the retina.

Finally, it is important to bear in mind that the other main photoreceptive regions of the vertebrate brain (the pineal and parapineal organs and the parietal eye) also arise as evaginations from the roof of the developing diencephalon. These organs are closely homologous with the lateral eyes, and a number of studies have highlighted the evolutionary significance of such parallels $s^{47,48,114-117}$.

Implications for the evolution of the vertebrate eye cup. With a degree of caution, one can interpret the developmental sequence described above, together with the findings set out earlier for ascidian, hagfish and lamprey eyes, as potentially providing clues about the evolution of the vertebrate eye. We now interpret these observations and propose the following scenario (see also BOX 2). 


\section{Müller cell}

A type of radial glial cell that provides support and nutrition in the retina. These cells appear to have an important (although not fully understood) role in the embryological development of the retina.
Before vision evolved, a common ancestor of hagfish, lampreys and jawed vertebrates possessed photosensitive ciliated epithelial cells that lined the ventricular surface of its brain. To aid light capture this region expanded, and in doing so part of it ballooned outwards laterally (see figure 7 of REF. 8). With the development of an overlying skull, the lateral lightsensitive region was better able to absorb light by expanding even further laterally. Light capture was additionally enhanced when an interaction between this 'eye vesicle' and the surface ectoderm, at what would become the lens placode, led to both invagination of

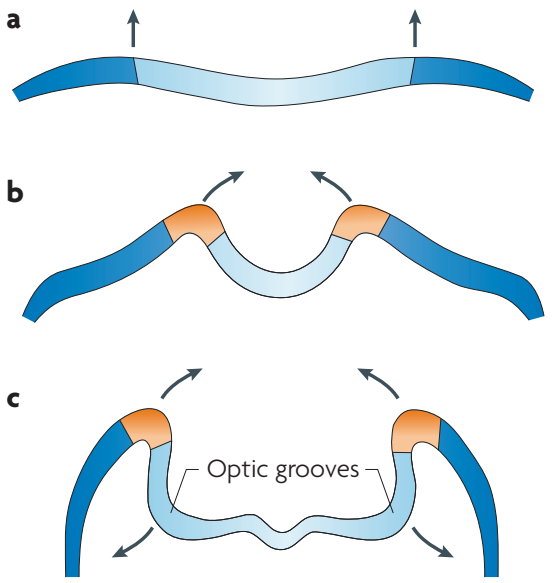

d

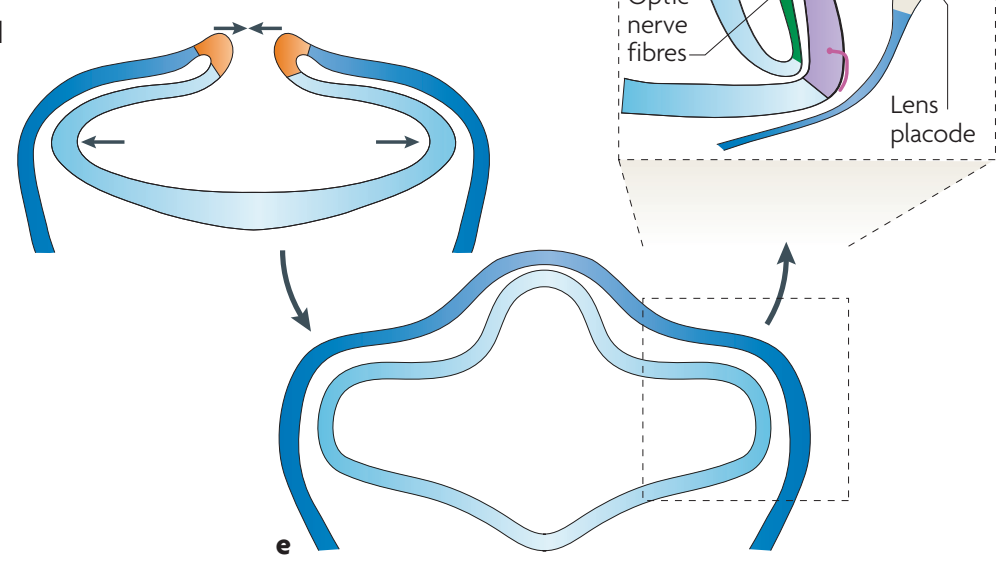

Figure 4 | Development of the vertebrate eye cup. a | The neural plate is the starting point for the development of the vertebrate eye cup. $\mathbf{b} \mid$ The neural plate folds upwards and inwards. $\mathbf{c | T h e}$ optic grooves evaginate. $\mathbf{d}$ | The lips of the neural folds approach each other and the optic vesicles bulge outwards. e |After the lips have sealed the neural tube is pinched off. At this stage the forebrain grows upwards and the optic vesicles continue to balloon outwards: they contact the surface ectoderm and induce the lens placode. $\mathbf{f} \mid$ The optic vesicle now invaginates, so that the future retina is apposed to the future retinal pigment epithelium (RPE), and the ventricular space that was between them disappears. Developing retinal ganglion cells send axons out across the retinal surface. The surface ectoderm at the lens placode begins to form the lens pit. This section is midline in the right eye, through the choroid fissure, so only the upper region of the retina and the RPE are visible. $\mathbf{g}$ |The eye cup grows circumferentially, eventually sealing over the choroidal fissure and enclosing the axons of the optic nerve (as well as the hyaloid/ retinal vessels; not shown). The ectodermal tissue continues to differentiate and eventually forms the lens. This figure is animated online (see Supplementary information S1). the eye cup and the prevention of pigmentation of the overlying skin. At this stage of evolution (by the end of stage 3, around $530 \mathrm{Mya}$ ) these lateral light-sensitive regions corresponded broadly to the 'eyes' of extant hagfish, lacking any imaging apparatus and presumably having a circadian or shadow-detection function rather than any role in image-forming vision.

In an ancestor of vertebrates (but not of hagfish) further development of the lens placode occurred, leading to the formation of a functional lens. In addition, extraocular muscles evolved from both neural crest and mesodermal tissue. In extant lampreys, these developmental events are delayed until metamorphosis, whereas in extant jawed vertebrates they follow on seamlessly after the lateral expansion of the eyes. In addition to these developments in imaging capabilities, it seems that advances in signal processing also occurred. Clues to the possible origin of such advances might be found by examining the development of retinal circuitry.

\section{The development of retinal neural circuitry}

The cell cycle in the vertebrate retina. Cells in the neuroepithelium of the optic vesicle, which will generate the retina, proceed through the standard cycle of replication in much the same way as cells in other regions of the brain, with the cell body following a clearly defined pattern of migration during the cycle (FIG. 5a; for a review, see REF. 54).

During G1 interphase, the soma of the cell migrates towards the inner (vitread) surface (FIG. 5a). Here the cell undergoes $\mathrm{S}$ phase, synthesizing DNA and replicating its chromosomes. During the subsequent G2 interphase, the tetraploid nucleus migrates back towards the outer (ventricular or sclerad) surface. At this outer surface, the cell undergoes mitosis ( $\mathrm{M}$ phase), separating into a pair of daughter cells, each of which can either exit the cell cycle (by entering the G0 phase) or continue through the cycle again. Once a cell has exited the cycle its soma migrates towards the final position that it will occupy in the retina once mature.

Three papers that were published in the late 1980s showed that dividing retinal progenitor cells can produce clones comprising any combination of cell types ${ }^{118-120}$. Thus, progenitor cells appear to be unrestricted in fate, with the capacity to form any class of retinal cell. There is currently intense research interest in the molecular mechanisms that underlie a retinal cell's fate choice ${ }^{121-125}$.

Order of genesis of cell classes. The order in which different classes of retinal cell are 'born' (defined as the time at which they exit the cell cycle) is highly conserved across vertebrate species (FIG. $5 b$ typifies the timing in mammalian retinae). During a first wave of cell genesis, retinal ganglion cells, horizontal cells, amacrine cells of at least one class and cone cells are born. A subsequent wave produces the remaining amacrine cells and also Müller cells. A third wave produces rod photoreceptors and finally bipolar cells (for a review, see REF. 54). 


\section{Photoreceptor development and maturation}

It has recently become apparent that cone and rod photoreceptors undergo several distinct phases of development ${ }^{126,127}$, and the following scenario has been established in the ferret retina.

Transient contacts at the inner plexiform layer. Initially (during the first post-natal week in the ferret) the photoreceptors have a simple bipolar form (FIG. 5c) and, in previous studies, they might have been incorrectly regarded as being uncommitted and/or undifferentiated. However, it is now clear that these young cells express markers that are specific for photoreceptors (for example, recoverin, vGluT1 and even rhodopsin) long before they exhibit the characteristic morphological features of mature photoreceptors. The somata of the young cones lie adjacent to the outer limiting membrane (OLM), whereas those of the young rods (which are born after the cones) lie slightly more vitread. Each photoreceptor soma is linked to the OLM by a short process.

Importantly, each young photoreceptor also projects a process directly to the inner plexiform layer (IPL), passing without contact through the outer plexiform layer (OPL) that is just beginning to form, even though horizontal cells, with which the photoreceptors will eventually connect, have already adopted their final positions in the vicinity of the future OPL. These a Stages of the cell cycle in the vertebrate retina

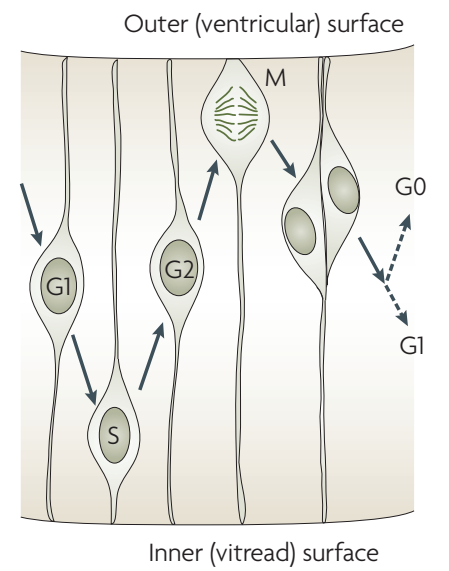

c At birth

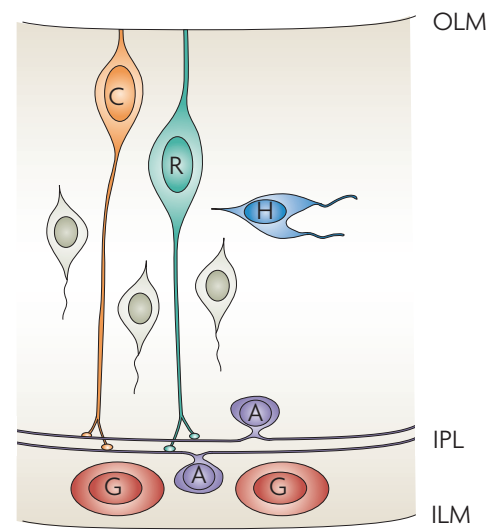

b Timing of cell birth in the vertebrate retina

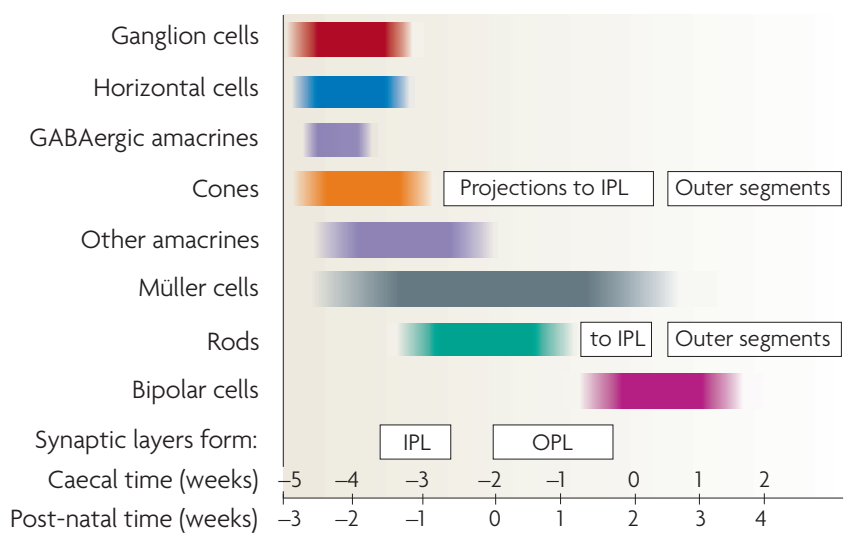

d 2 weeks
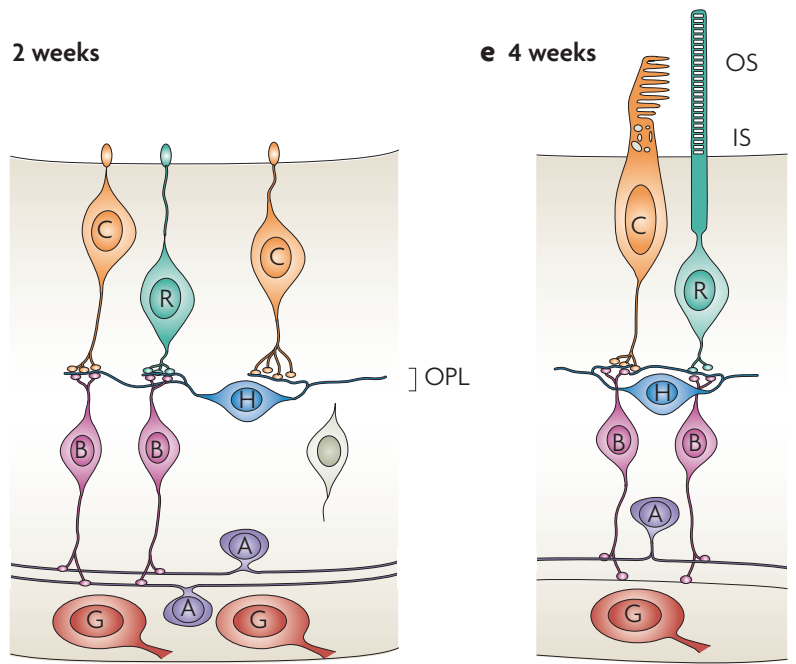

Figure 5 | The development of retinal neurons and circuitry. a | The cell cycle in the vertebrate retina. The soma of a replicating cell migrates between the outer (ventricular) surface, where mitosis (M) occurs, and the inner (vitread) surface. $\mathbf{b}$ |The sequential birth of cell classes in the vertebrate retina, with timings indicated for the ferret in both post-natal weeks and caecal time (that is, the time relative to eye opening), which is probably a better comparator for other species $^{173}$. $\mathbf{c}-\mathbf{e} \mid$ The maturation of neural connectivity in the retina ${ }^{126,127,174}$ (again, timings are for the ferret). c Initially photoreceptors (which exhibit few adult morphological characteristics) send transient processes to the inner plexiform layer (IPL), where they make synaptic contacts with the two sub-laminae. $\mathbf{d}$ | Subsequently these processes retract, and developing bipolar cells insert themselves into the pathway between the photoreceptors and the inner nuclear layer (INL). e $\mid$ At a later stage, the rod and cone photoreceptors develop inner segments (IS) and outer segments (OS). A, amacrine cell; B, bipolar cell; C, cone photoreceptor cell; G, ganglion cell; H, horizontal cell; ILM, inner limiting membrane; OLM, outer limiting membrane; OPL, outer plexiform layer; R, rod photoreceptor cell. 
events are independent of the formation of Müller cells. Within the IPL the photoreceptor processes terminate in two discrete sub-layers, coincident with the stratifying processes of cholinergic amacrine cells. The photoreceptor terminals express the synaptic proteins synaptophysin and synaptotagmin, and have the morphological appearance of functional synapses ${ }^{126}$. However, it has not been established whether the postsynaptic processes that they contact are amacrine or ganglion cells.

Mature contacts at the outer plexiform layer. Subsequent to the formation of transient contacts, at approximately post-natal day 14 in the ferret, these transient processes retract from the IPL and the photoreceptors instead make synaptic contacts in the developing OPL (FIG. 5d). This phase of retraction coincides with maturation of the bipolar cells and with continued maturation of horizontal cells and the OPL. At the developing OPL each photoreceptor terminal first forms a dyad contact with a pair of horizontal cell processes and is thereafter contacted by a bipolar cell process, giving rise to the adult triad arrangement of the ON pathway.

This developmental sequence, in which an initial direct synaptic contact from the photoreceptor to the ganglion cell is followed by the subsequent insertion of a bipolar cell between the two cells, suggests that a comparable sequence of events might have occurred during the evolution of the retina in the transition from a hagfish-like retina to a vertebrate-like retina ${ }^{109}$.

Elaboration of the inner and outer segments. At approximately the time that synaptic contacts form at the OPL, the distal process of each photoreceptor penetrates the outer limiting membrane and begins to form an inner segment and an outer segment (FIG. 5e). Hence, it is not until at least this stage of retinal development that conventional visual transduction becomes possible.

\section{The origin of retinal bipolar cells}

Retinal bipolar cells share a large repertoire of features with rod and cone photoreceptors. Structurally, retinal bipolar cells have the same 'bipolar' shape that developing photoreceptors have before their inner and outer segments differentiate (FIG. 5c). Bipolar cells develop an appendage (the Landolt club) that bears a striking similarity to the outer segment of the photoreceptor: it has microtubules that are organized in the $9+0$ pattern that is characteristic of non-motile cilia and it is located at the outer limiting membrane, although it lacks disc membranes. In terms of transduction mechanisms, the G-protein signalling cascade of the ON bipolar cells bears a remarkable similarity to the phototransduction cascade in photoreceptors. In addition, the output synapse of the bipolar cell is very similar to that of the photoreceptor, in that it uses synapticribbon structures that are not found in other types of retinal neuron. Finally, many of the proteins that are expressed in bipolar cells are either identical to, or else represent isoforms of, proteins that are found in cone and rod photoreceptors - for example, recoverin, potassium channels and the molecular machinery of ribbon synapses.

One possibility that might account for these observations is that photoreceptors and bipolar cells are independent descendants of the 'protoneuron' that is proposed to have been the most ancient type of vertebrate nerve cell ${ }^{114,115}$. An extant representative of this protoneuron appears to be the sensory cerebrospinal fluid (CSF)-contacting neuron that is present in the CNS of lancelets, hagfish ${ }^{128}$ and lampreys ${ }^{129}$ as well as jawed vertebrates. An alternative scenario could be that bipolar cells evolved from ciliary photoreceptors. In this case one might anticipate that, whereas cone ON bipolar cells would have descended from cones, rod bipolar cells might have descended from rods, rather than from cone bipolar cells.

\section{Biplexiform ganglion cells}

In addition to the transient embryonic contacts of photoreceptors onto ganglion cells described above, direct contacts from photoreceptors to ganglion cells are maintained in the adult retina. Biplexiform ganglion cells are a class of retinal projection neuron that seem to exist in all vertebrate species from lamprey to primate $^{37,130-133}$, and which receive synaptic input from photoreceptors as well as from bipolar cells. In addition, the lamprey has a class of ganglion cell that might contact only photoreceptors ${ }^{132}$. Hence, it seems possible that such cells might represent a primordial form of retinal projection neuron that originated before the evolution of bipolar cells. The lamprey retina is also interesting in that the majority of ganglion cells (and nerve fibres) lie distal to, rather than proximal to, the IPL (see figure 7 of REF. 37). This might represent the primordial layering arrangement of the vertebrate retina, in which case an inversion of layers through altered patterns of radial migration might have occurred in the gnathostome retina.

\section{Proposed evolutionary sequence}

Some of the most fundamental events in the evolution of the vertebrate eye occurred in the relatively short time of a few tens of millions of years, around the time of the Cambrian explosion more than 500 Mya and possibly coincident with two duplications of the entire genome.

First, it seems likely that a basal chordate possessed simple paired photoreceptive organs that were broadly similar to the unpaired organs of extant Amphioxus and C. intestinalis (it seems very likely that during evolution $C$. intestinalis has lost one member of what was once a pair ${ }^{77}$ ). By approximately 530 Mya these paired organs had expanded laterally, and each had developed into a two-layered 'retina', with ciliary photoreceptors contacting projection neurons (which might have arisen from rhabdomeric photoreceptor cells). The resultant organ would have been quite similar to the 'eye' of extant hagfish, with a circadian and/or shadow-detecting function and a lack of optical components for imaging. The advantage it conferred to the animal was the ability 
to gather much more light (possibly at great depth), through a large increase in the number of photoreceptors, through lateral positioning outside the skull and through de-pigmentation of the overlying skin.

Subsequently, in evolutionary steps that closely parallelled the developmental steps that occur in extant metamorphosing lampreys, this rudimentary eye acquired a lens, an increase in retinal processing power (through the insertion of retinal bipolar cells), projection of the ganglion cell axons to thalamic regions, and extraocular muscles. This eye, which was equivalent to the eye of adult extant lampreys, possessed almost all

\section{Box 2 | Proposed sequence of events involved in the evolution of the vertebrate eye}

\author{
Stage 1: bilateral ancestor ( $>580$ million years ago $(\mathrm{Mya})$ ) \\ - Animals with bilateral symmetry exist ${ }^{2}$. \\ - Numerous families of genes exist ${ }^{22}$. \\ - A range of G-protein-coupled signalling cascades exist ${ }^{146}$. \\ - A primordial opsin has evolved into three major classes: rhabdomeric \\ opsins, photoisomerase-like opsins and ciliary opsins ${ }^{147}$. \\ - A rhabdomeric-type photoreceptor has evolved, using a $\mathrm{G}_{\mathrm{q}}$-based \\ signalling cascade with a rhabdomeric opsin ${ }^{9}$. \\ - A ciliary-type photoreceptor has evolved, using a variant opsin (the \\ stem ciliary opsin) that probably coupled to a $\mathrm{G}_{\mathrm{o}}$-based signalling \\ cascade a $^{8,61,92,148}$ \\ $\sim 580$ Mya \\ - Protostomes separate from our line (deuterostomes).
}

Stage 2: protochordates (580-550 Mya)

- The ciliary photoreceptor and ciliary opsin continue to evolve, becoming

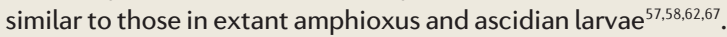

- A primordial RPE65-like isomerase evolves ${ }^{62,65}$.

These protochordates had ciliary photoreceptors with a ciliary opsin and a hyperpolarizing response, and were able to regenerate 11-cis retinal in darkness.

\section{$\sim 550$ Mya}

- Cephalochordates and tunicates separate from our line (chordates).

Stage 3: ancestral craniates ( 550-530 Mya)

- A ciliary photoreceptor evolves that has well organized outer-segment membranes, an output synapse close to the soma and a synaptic specialization appropriate for graded signal transmission ${ }^{42,86}$.

- Ciliary photoreceptors make synaptic contact onto projection neurons that might have been descendants of rhabdomeric photoreceptors ${ }^{9,69}$.

- The eye-field region of the diencephalon bulges to form lateral 'eye vesicles $^{149}$.

- These lateral vesicles invaginate, bringing the proto-retina into apposition with the proto-retinal pigment epithelium ${ }^{149}$.

- A primordial lens placode develops, preventing pigmentation of the overlying $\operatorname{skin}^{145}$.

The resulting paired lateral photoreceptive organs would have resembled the 'eyes' of extant hagfish, lacking any image-forming apparatus and subserving non-visual functions.

\section{$\sim 530$ Mya}

- Myxiniformes (hagfish) separate from our line (vertebrates).

\section{Stage 4: lamprey-like ancestors ( 530-500 Mya)}

- Photoreceptors develop cone-like features:

- Highly-ordered sac/disc membranes evolve ${ }^{81}$.

- Mitochondria become concentrated within the ellipsoid region of the inner segment ${ }^{81}$.

- Coloured filter material is incorporated into the inner segment for spectral tuning ${ }^{83}$.

- Ribbon synapses evolve in the synaptic terminal ${ }^{78}$.

- Genome duplications give rise to multiple copies of the phototransduction genes ${ }^{23,24,28,29}$.
- Cell classes diverge to give five separate cone-like photoreceptors, each with its own ciliary opsin and with isoforms of transduction proteins $^{38,90,93,108}$.

- Retinal computing power increases:

- Cone bipolar cells evolve, either from proto-neurons or from photoreceptors ${ }^{114,150}$.

- The bipolar cells insert into the pathway from photoreceptors to ganglion cells, through the retraction of photoreceptor processes and the incorporation of new contacts ${ }^{114,126}$.

- Bi-plexiform ganglion cells develop ${ }^{37}$.

- A highly organized three-layered neuronal structure with two intervening plexiform layers develops ${ }^{50,51}$.

- Ganglion-cell axons project to the thalamus ${ }^{44,45}$.

- The optics evolve (the lens, accommodation and eye movement):

- The lens placode invaginates and develops to form a lens ${ }^{151}$.

- The iris develops and a degree of pupillary constriction becomes possible ${ }^{84}$.

- Innervated extra-ocular muscles evolve ${ }^{152}$.

The resulting eye and visual system would have resembled that in extant lampreys and would have provided spatial vision at photopic intensities and over a broad wavelength range.

\section{$\sim 500$ Mya}

- Petromyzoniformes (lampreys) separate from our line.

\section{Stage 5: jawless fish ( 500-430 Mya)}

- Myelin evolves and is incorporated throughout the nervous system ${ }^{153}$.

- Rod photoreceptors evolve:

- Rhodopsin evolves from cone opsin ${ }^{38,93}$.

- Rod isoforms of most transduction cascade proteins arise $\mathrm{e}^{90,108}$.

- Free-floating discs pinch off within the plasma membrane.

- Rod bipolar cells evolve, possibly from rod photoreceptors ${ }^{114}$.

- The scotopic rod pathway evolves, with a new subset of amacrine cells (All) providing input into the pre-existing cone pathway ${ }^{154,155}$.

- A highly contractile iris evolves that can adjust light levels ${ }^{156}$.

- Intrinsic eye muscles develop that permit accommodation of the lens ${ }^{157}$.

This eye possessed a duplex retina that contained both rods and cones, together with retinal wiring that closely resembled that of jawed vertebrates, with colour-coded photopic pathways and a dedicated scotopic pathway; it was probably similar to that found in many extant fish.

\section{$\sim 430$ Mya}

- The last jawless fish separate from our own line (gnathostomes).

Stage 6: gnathostomes (<430 Mya).

- In the case of tetrapods:

- The lens develops an elliptical shape to compensate for the added refractive power that is provided by the cornea in air ${ }^{158}$.

- The dermal component of the split cornea is lost and the eyelids evolve ${ }^{149}$.

- Certain opsin classes are lost, for example, SWS2 and Rh2 in mammals, under extended nocturnal conditions $\mathrm{s}^{159}$. 
of the crucial features that characterize the modern vertebrate eye, and was present at least 500 Mya. Along with this transformation of the hagfish-like lateral organs from a non-imaging function to an imaging function, another region of the diencephalon expanded to take over circadian function and evolved into the pineal organ.

The evolutionary steps that we propose are set out as an explicit scenario in BOX 2, and it can be seen that a number of these steps are retained during the development of modern embryos. In our view a case can be made that a great number of these proposed steps are likely to have been advantageous to the animals that evolved them; indeed, for the optical features, an assessment of the performance of the various stages of eye cup and lens development has previously been presented ${ }^{134}$. Accordingly, we think that this proposed sequence might satisfy Darwin's prescription for the evolution of the vertebrate eye.

\section{Conclusions and perspectives}

We have conducted a comparative analysis of the features of opsins, photoreceptors, retinal connectivity and eye morphology, across organisms that range from sea-squirts to hagfish, lampreys and jawed vertebrates. By combining this analysis with a consideration of the embryological development of the mammalian eye, we have been able to discern what we believe to be a long sequence of transitions that we postulate have underlain the evolution of the vertebrate eye.

Our hypotheses are open to test, because they lead to a number of explicit predictions, several of which we present in BOX 3. Clearly, a great deal rests on establishing the precise status of the hagfish: that is, on clarifying the details of its retinal circuitry and its correct phylogenetic position. By undertaking experiments of the kind indicated in BOX 3, it should be possible, within a relatively short time, to support, revise, or rule out the ideas that we have gathered here.

\section{Box 3 | Predictions and tests of our hypotheses of vertebrate eye evolution}

Prediction 1: the phototransduction cascade components of tunicate ocelli should be homologous with those of hagfish and lamprey photoreceptors.

- Identify the $\mathrm{G}$ protein of Ciona intestinalis photoreceptors and compare it with those of hagfish, lampreys and jawed vertebrates.

- Determine whether other homologous cascade components (for example, phosphodiesterase and cyclic-nucleotidegated channels) are present in tunicate photoreceptors.

- Determine the genomic organization of these cascade components and compare it with that of jawed vertebrates.

Prediction 2: at an early stage of eye evolution there was synaptic contact from ciliary photoreceptors onto rhabdomeric photoreceptors.

- Examine whether synaptic contacts occur between ciliary and rhabdomeric photoreceptors in extant protochordates, such as Amphioxus and C. intestinalis.

- Examine whether microvillar opsin-containing membranes are retained in the retinal projection neurons (ganglion cells) of any extant organism.

Prediction 3: hagfish photoreceptors should exhibit close homology to cones.

- Identify the ciliary opsin (or opsins) of hagfish and determine its (or their) phylogenetic relationship to other ciliary opsins.

- Identify the principal phototransduction proteins (the G protein, the phosphodiesterase and the cyclic-nucleotide-gated channels) in hagfish, and determine their phylogenetic relationship to vertebrate cone and rod isoforms.

- Measure the electrical light responses and light adaptation of hagfish photoreceptors, and compare these with cone and rod responses.

Prediction 4: the hagfish retina should not contain bipolar cells, and its photoreceptors should synapse directly onto the projection neurons (ganglion cells).

- Use retrograde labelling of hagfish ganglion cells to examine their synaptic inputs.

- Use Golgi labelling of hagfish retina to investigate the connectivity of different cell classes.

- Examine the synaptic contacts between cell classes at the ultrastructural level.

Prediction 5: if hagfish are monophyletic with lampreys, then they might represent a form with arrested development, rather than a degenerate form.

- Examine the phylogenetic relationship between cyclostome genes; in particular, examine the relationship between the opsin genes to estimate the stage at which hagfish diverged.

Prediction 6: lampreys ought not to possess true rods.

- Further characterize the photoreceptors of other extant species of lamprey to ascertain whether the morphological and electrophysiological features of true rods are present.

- Further characterize the opsins of lampreys, to ascertain whether the RhA/Rh1 pigment can be considered equivalent to a rhodopsin.

Prediction 7: lampreys should not possess rod bipolar cells.

- Carry out an immunohistochemical characterization of bipolar cell classes in the lamprey retina.

- Carry out an electrophysiological characterization of lamprey bipolar cells.

Prediction 8: if vertebrate bipolar cells are descended from photoreceptors they will share numerous molecular components or have very close homologues.

- Compare the molecular components of cone and rod bipolar cells with those of cones and rods. 
1. Darwin, C. On the Origin of Species by Means of Natural Selection, or the Preservation of Favoured Races in the Struggle for Life 186 (John Murray, London, 1859).

2. Conway Morris, S. The Cambrian "explosion": slow fuse or megatonnage? Proc. Natl Acad. Sci. USA 97 4426-4429 (2000).

3. Conway Morris, S. Evolution: bringing molecules into the fold. Cell 100, 1-11 (2000).

This paper provides an illuminating analysis of the conflicts between the classical (paleontological and morphological) approaches to understanding evolution and the more recent molecular approaches.

4. Conway Morris, S. Darwin's dilemma: the realities of the Cambrian 'explosion'. Philos. Trans. R. Soc. Lond. B Biol. Sci. 361, 1069-1083 (2006).

5. Dawkins, R. \& Krebs, J. R. Arms races between and within species. Proc. R. Soc. Lond. B Biol. Sci. 205 489-511 (1979).

6. Gehring, W. J. Historical perspective on the development and evolution of eyes and photoreceptors. Int. J. Dev. Biol. 48, 707-717 (2004)

Fernald, R. D. in Evolution of Nervous Systems: A Comprehensive Reference. Vol. 2: Non-Mammalian Vertebrates (eds Kaas, J. H. \& Bullock, T. H.) 335-348 (Elsevier, Amsterdam, 2007).

8. Arendt, D. \& Wittbrodt, J. Reconstructing the eyes of Urbilateria. Philos. Trans. R. Soc. Lond. B Biol. Sci. 356, 1545-1563 (2001)

9. Arendt, D. Evolution of eyes and photoreceptor cell types. Int. J. Dev. Biol. 47, 563-571 (2003). This paper, along with reference 8 , lays the cellular and molecular foundations for identifying homologous types of visual cell across bilateral animals.

10. Land, M. F. \& Nilsson, D.-E. Animal Eyes (Oxford Univ. Press, New York, 2002)

11. Janvier, P. Early Vertebrates (Oxford Univ. Press, Oxford, UK, 1996).

12. Xian-Guang, H., Aldridge, R. J., Siveter, D. J., Siveter, D. J. \& Xiang-Hong, F. New evidence on the anatomy and phylogeny of the earliest vertebrates. Proc. $R$. Soc. Lond. B Biol. Sci. 269, 1865-1869 (2002)

13 Shu, D. G. et al. Head and backbone of the Early Cambrian vertebrate Haikouichthys. Nature 421 526-529 (2003)

14. Gradstein, F. M., Ogg, J. G. \& Smith, A. G. A Geologic Time Scale 2004 (Cambridge Univ. Press, Cambridge, UK, 2005)

15. Gess, R. W., Coates, M. I. \& Rubidge, B. S. A lamprey from the Devonian period of South Africa. Nature 443, 981-984 (2006)

16. Janvier, P. Palaeontology: modern look for ancient lamprey. Nature 443, 921-924 (2006)

17. Benton, M. J. \& Donoghue, P. C. J. Paleontological evidence to date the tree of life. Mol. Biol. Evol. 24 26-53 (2007)

18. Donoghue, P. C. \& Benton, M. J. Rocks and clocks: calibrating the tree of life using fossils and molecules. Trends Ecol. Evol. 22, 424-431 (2007).

19. Welch, J. J., Fontanillas, E. \& Bromham, L. Molecular dates for the "Cambrian explosion": the influence of prior assumptions. Syst. Biol. 54, 672-678 (2005)

20. Welch, J. J. \& Bromham, L. Molecular dating when rates vary. Trends Ecol. Evol. 20, 320-327 (2005).

21. Thomas, J. A., Welch, J. J., Woolfit, M. \& Bromham, L. There is no universal molecular clock for invertebrates, but rate variation does not scale with body size. Proc. Natl Acad. Sci. USA 103, 7366-7371 (2006).

22. Suga, H. et al. Extensive gene duplication in the early evolution of animals before the parazoan-eumetazoan split demonstrated by $\mathrm{G}$ proteins and protein tyrosine kinases from sponge and hydra. J. Mol. Evol. 48 , 646-653 (1999).

23. Ohno, S. Evolution by Gene Duplication (Allen \& Unwin, London, 1970).

24. Holland, P. W. H., García-Fernández, J. M., Williams, N. A. \& Sidow, A. Gene duplications and the origins of vertebrate development. Development (Suppl.) 125-133 (1994)

25. Sidow, A. Gen(om)e duplications in the evolution of early vertebrates. Curr. Opin. Genet. Dev. 6, 715-722 (1996).

This paper provides a summary of the evidence for and the role of, early genome duplications in vertebrate evolution

26. Furlong, R. F. \& Holland, P. W. H. Were vertebrates octoploid? Philos. Trans. R. Soc. Lond. B Biol. Sci. 357, 531-544 (2002).
27. Lundin, L. G., Larhammar, D. \& Hallböök, F Numerous groups of chromosomal regional paralogies strongly indicate two genome doublings at the root of the vertebrates. J. Struct. Funct. Genomics 3, 53-63 (2003).

28. Fredriksson, R., Lagerström, M. C., Lundin, L. G. \& Schiöth, H. B. The G-protein-coupled receptors in the human genome form five main families. Phylogenetic analysis, paralogon groups, and fingerprints. Mol. Pharmacol. 63, 1256-1272 (2003).

29. Nordström, K., Larsson, T. A. \& Larhammar, D. Extensive duplications of phototransduction genes in early vertebrate evolution correlate with block (chromosome) duplications. Genomics 83, 852-872 (2004).

This paper summarizes the blocks of human phototransduction genes that are likely to have arisen from genome duplications in early vertebrate evolution.

30. Escriva, H., Manzon, L., Youson, J. \& Laudet, V. Analysis of lamprey and hagfish genes reveals a complex history of gene duplications during early vertebrate evolution. Mol. Biol. Evol. 19, 1440-1450 (2002).

31. Dehal, P. \& Boore, J. L. Two rounds of whole genome duplication in the ancestral vertebrate. PLoS Biol. 3 , 1700-1708 (2005)

32. Panopoulou, G. \& Poustka, A. J. Timing and mechanism of ancient vertebrate genome duplications - the adventure of a hypothesis. Trends Genet. 21, 559-567 (2005)

33. Gerhart, J. Evolution of the organizer and the chordate body plan. Int. J. Dev. Biol. 45, 133-153 (2001).

34. Yu, J. K. et al. Axial patterning in cephalochordates and the evolution of the organizer. Nature 445 613-617 (2007).

35. Holland, L. Z. \& Holland, N. D. A revised fate map for amphioxus and the evolution of axial patterning in chordates. Integr. Comp. Biol. 47, 360-372 (2007).

36. Holmberg, K. in Handbook of Sensory Physiology, Vol. VII/5, The visual system of vertebrates (ed. Crescitelli, F.) 47-66 (Springer, Berlin, 1977) This paper provides an excellent summary of the ultrastructure of hagfish and lamprey eyes, providing a basis for comparison with jawed vertebrates.

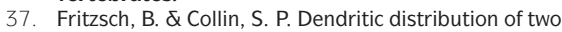 populations of ganglion cells and the retinopetal fibers in the retina of the silver lamprey (Ichthyomyzon unicuspis). Vis. Neurosci. 4, 533-545 (1990).

38. Collin, S. P. et al. Ancient colour vision: multiple opsin genes in the ancestral vertebrates. Curr. Biol. 13, R864-R865 (2003)

This study presents the discovery in lampreys of five retinal opsins that are homologous to the four classes of cone opsin and rhodopsin in vertebrates.

39. Locket, N. A. \& Jorgensen, J. M. in The Biology of Hagfishes (eds Jorgensen, J. M., Lomholt, J. P., Weber, R. E. \& Malte, H.) 541-556 (Chapman and Hall, London, 1998)

This paper provides the most comprehensive description of the eyes of hagfish.

40. Fernholm, B. \& Holmberg, K. The eyes in three genera of hagfish (Eptatretus, Paramyxine and Myxine) - a case of degenerative evolution. Vision Res. 15 253-259 (1975)

41. Kobayashi, H. On the photo-perceptive function in the eye of the hagfish, Myxine garmani Jordan et Snyder J. Natl Fish. Univ. 13, 67-83 (1964).

42. Holmberg, $K$. The hagfish retina: fine structure of retinal cells in Myxine glutinosa, L., with special reference to receptor and epithelial cells. Z. Zellforsch. Mikrosk. Anat. 111, 519-538 (1970).

43. Holmberg, K. The hagfish retina: electron microscopic study comparing receptor and epithelial cells in Pacific hagfish, Polistotrema stouti, with those in Atlantic hagfish, Myxine glutinosa. Z. Zellforsch. Mikrosk. Anat. 121, 249-269 (1971).

44. Kusunoki, T. \& Amemiya, F. Retinal projections in the hagfish, Eptatretus burgeri. Brain Res. 262, 295-298 (1983).

45. Wicht, H. \& Northcutt, R. G. Retinofugal and retinopetal projections in the Pacific hagfish Eptatretus stouti (Myxinoidea). Brain Behav. Evol. 36, 315-328 (1990).

46. Hattar, S. et al. Central projections of melanopsinexpressing retinal ganglion cells in the mouse. J. Comp. Neurol. 497, 326-349 (2006).

47. Vigh, B. et al. The pineal organ as a folded retina: immunocytochemical localization of opsins. Biol. Cell 90, 653-659 (1998).
48. Ekström, P. \& Meissl, H. Evolution of photosensory pineal organs in new light: the fate of neuroendocrine photoreceptors. Philos. Trans. R. Soc. Lond. B Biol. 358, 1679-1700 (2003)

49. Newth, D. R. \& Ross, D. M. On the reaction to light of Myxine glutinosa L. J. Exp. Biol. 32, 4-21 (1955).

50. Dickson, D. H. \& Collard, T. R. Retinal development in the lamprey (Petromyzon marinus L.): premetamorphic ammocoete eye. Am. J. Anat. 154, 321-336 (1979)

51. Rubinson, K. \& Cain, H. Neural differentiation in the retina of the larval sea lamprey (Petromyzon marinus) Vis. Neurosci. 3, 241-248 (1989).

52. Rubinson, K. The developing visual system and metamorphosis in the lamprey. J. Neurobiol. 21 1123-1135 (1990)

53. Meyer-Rochow, V. B. \& Stewart, D. Review of larval and postlarval eye ultrastructure in the lamprey (Cyclostomata) with special emphasis on Geotria australis (Gray). Microsc. Res. Tech. 35, 431-444 (1996).

54. Rapaport, D. H. in Retinal Development (eds Sernagor, E., Eglen, S., Harris, W. \& Wong, R.) 30-58 (Cambridge Univ. Press, Cambridge, UK, 2006)

55. Dickson, D. H., Graves, D. A. \& Moyles, M. R. Corneal splitting in the developing lamprey Petromyzon marinus L. eye. Am. J. Anat. 165, 83-98 (1982)

56. Delsuc, F., Brinkmann, H., Chourrout, D. \& Philippe, H. Tunicates and not cephalochordates are the closest living relatives of vertebrates. Nature 439, 965-968 (2006).

This paper presents a molecular-genetic analysis that reverses the earlier view that cephalochordates are closer to our own ancestors than are tunicates.

57. Dilly, N. Studies on the receptors in the cerebral vesicle of the ascidian tadpole. 2 . The ocellus. Q. J. Microsc. Sci. 105, 13-20 (1964).

58. Eakin, R. M. \& Kuda, A. Ultrastructure of sensory receptors in ascidian tadpoles. Z. Zellforsch. Mikrosk. Anat. 112, 287-312 (1971)

59. Barnes, S. N. Fine structure of the photoreceptor and cerebral ganglion of the tadpole larva of Amaroucium constellatum (Verril) (subphylum: Urochordata; class: Ascidiacea). Z. Zellforsch Mikrosk. Anat. 117, 1-16 (1971).

60. Gorman, A. L. F., McReynolds, J. S. \& Barnes, S. N Photoreceptors in primitive chordates: fine structure, hyperpolarizing receptor potentials, and evolution. Science 172, 1052-1054 (1971)

61. Kusakabe, T. et al. Ci-opsin 1, a vertebrate-type opsin gene, expressed in the larval ocellus of the ascidian Ciona intestinalis. FEBS Lett. 506, 69-72 (2001).

62. Tsuda, M. et al. Origin of the vertebrate visual cycle: II. Visual cycle proteins are localized in whole brain including photoreceptor cells of a primitive chordate. Vis. Res. 43, 3045-3053 (2003).

63. D'Aniello, S et al. The ascidian homolog of the vertebrate homeobox gene $R x$ is essential for ocellus development and function. Differentiation 74 222-234 (2006)

64. Sato, S. \& Yamamoto, H. Development of pigment cells in the brain of ascidian tadpole larvae: insights into the origins of vertebrate pigment cells. Pigment Cell Res. 14, 428-436 (2001)

65. Takimoto, N., Kusakabe, T., Horie, T., Miyamoto, Y. \& Tsuda, M. Origin of the vertebrate visual cycle: III. Distinct distribution of RPE65 and $\beta$-carotene 15,15'-monooxygenase homologues in Ciona intestinalis. Photochem. Photobiol. 82, 1468-1474 (2006).

This study is the third in a series of investigation into the origin of the isomerohydrolase (RPE65) enzyme in an early chordate organism.

66. Lacalli, T. C. Frontal eye circuitry, rostral sensory pathways and brain organization in amphioxus larvae: evidence from 3D reconstructions. Philos. Trans. $R$. Soc. Lond. B Biol. Sci. 351, 243-263 (1996).

67. Lacalli, T. C. Sensory systems in amphioxus: a window on the ancestral chordate condition. Brain Behav. Evol. 64, 148-162 (2004).

This paper provides a summary of the rhabdomeric and ciliary photoreceptor organs in the primitive chordate amphioxus.

68. Koyanagi, M., Terakita, A., Kubokawa, K. \& Shichida Y. Amphioxus homologs of Go-coupled rhodopsin and peropsin having 11-cis- and all-trans-retinals as their chromophores. FEBS Lett. 531, 525-528 (2002). 
69. Koyanagi, M., Kubokawa, K., Tsukamoto, H., Shichida, Y. \& Terakita, A. Cephalochordate melanopsin: evolutionary linkage between invertebrate visual cells and vertebrate photosensitive retinal ganglion cells. Curr. Biol. 15, 1065-1069 (2005).

This paper provides an examination of the homologue of rhabdomeric-like vertebrate opsin, melanopsin, which is found in the primitive chordate amphioxus, and of the link between invertebrates and vertebrates.

70. Schubert, M., Escriva, H., Xavier-Neto, J. \& Laudet, V. Amphioxus and tunicates as evolutionary model systems. Trends Ecol. Evol. 21, 269-277 (2006).

71. Beaster-Jones, L., Horton, A. C., Gibson-Brown, J. J., Holland, N. D. \& Holland, L. Z. The amphioxus T-box gene, AmphiTbx 15/18/22, illuminates the origins of chordate segmentation. Evol. Dev. 8, 119-129 (2006).

72. Arendt, D., Tessmar-Raible, K., Snyman, H. Dorresteijn, A. W. \& Wittbrodt, J. Ciliary photoreceptors with a vertebrate-type opsin in an invertebrate brain. Science 306, 869-871 (2004). This study presents the discovery that an invertebrate (protostome) species possessed ciliary photoreceptors expressing a ciliary opsin, in addition to rhabdomeric photoreceptors expressing a rhabdomeric opsin.

73. Yokoyama, S. Molecular evolution of vertebrate visual pigments. Prog. Retin. Eye Res. 19, 385-419 (2000).

74. Nasi, E., del Pilar Gomez, M. \& Payne, R. in Molecular Mechanisms of Visual Transduction (eds Stavenga, D. G., de Grip, W. J. \& Pugh, E. N. J.) 389-448 (Elsevier, Amsterdam, 2000)

75. Velarde, R. A., Sauer, C. D., Walden, K. K. O. Fahrbach, S. E. \& Robertson, H. M. Pteropsin: a vertebrate-like non-visual opsin expressed in the honey bee brain. Insect Biochem. Mol. Biol. 35, 1367-1377 (2005).

76. Arendt, D., Tessmar, K., de Campos-Baptista, M. I. M., Dorresteijn, A. \& Wittbrodt, J. Development of pigment-cup eyes in the polychaete Platynereis dumerilii and evolutionary conservation of larval eyes in Bilateria. Development 129, 1143-1154 (2002).

77. Imai, J. H. \& Meinertzhagen, I. A. Neurons of the ascidian larval nervous system in Ciona intestinalis: I. Central nervous system. J. Comp. Neurol. 501 316-334 (2007)

78. Pu, G. A. \& Dowling, J. E. Anatomical and physiological characteristics of pineal photoreceptor cell in the larval lamprey, Petromyzon marinus. J. Neurophysiol. 46, 1018-1038 (1981).

79. Samejima, M., Tamotsu, S., Watanabe, K. \& Morita, Y Photoreceptor cells and neural elements with long axonal processes in the pineal organ of the lamprey, Lampetra japonica, identified by use of the horseradish peroxidase method. Cell Tissue Res. 258 219-224 (1989)

80. Govardovskii, V. I. \& Lychakov, D. V. Visual cells and visual pigments of the lamprey, Lampetra fluviatilis. J. Comp. Physiol. A 154, 279-286 (1984).

81. Collin, S. P., Potter, I. C. \& Braekevelt, C. R. The ocular morphology of the southern hemisphere lamprey Geotria australis Gray, with special reference to optical specialisations and the characterisation and phylogeny of photoreceptor types. Brain Behav. Evol. 54 , 96-118 (1999).

82. Collin, S. P. \& Potter, I. C. The ocular morphology of the southern hemisphere lamprey Mordacia mordax Richardson with special reference to a single class of photoreceptor and a retinal tapetum. Brain Behav. Evol. 55, 120-138 (2000).

83. Collin, S. P., Hart, N. S., Shand, J. \& Potter, I. C. Morphology and spectral absorption characteristics of retinal photoreceptors in the southern hemisphere lamprey (Geotria australis). Vis. Neurosci. 20, 119-30 (2003).

84. Collin, S. P., Hart, N. S., Wallace, K. M., Shand, J. \& Potter, I. C. Vision in the southern hemisphere lamprey Mordacia mordax: spatial distribution, spectral absorption characteristics, and optical sensitivity of a single class of retinal photoreceptor. Vis. Neurosci. 21, 765-773 (2004)

85. Collin, S. P. $\&$ Trezise, A. E. The origins of colour vision in vertebrates. Clin. Exp. Optom. 87, 217-23 (2004).

86. Holmberg, K. \& Öhman, P. Fine structure of retinal synaptic organelles in lamprey and hagfish photoreceptors. Vision Res. 16, 237-239 (1976).

87. Vollrath, L., Meyer, A. \& Buschmann, F. Ribbon synapses of the mammalian retina contain two types of synaptic bodies - ribbons and spheres. J. Neurocytol. 18, 115-120 (1989).
88. Wagner, H.-J. Presynaptic bodies ("ribbons"): from ultrastructural observations to molecular perspectives. Cell Tissue Res. 287, 435-446 (1997)

89. Davies, W. L. et al. Functional characterization, tuning, and regulation of visual pigment gene expression in an anadromous lamprey. FASEB J. 21, 2713-2724 (2007).

90. Hisatomi, O. \& Tokunaga, F. Molecular evolution of proteins involved in vertebrate phototransduction. Comp. Biochem. Physiol. Biochem. Mol. Biol. 133 509-522 (2002).

91. Shichida, Y. \& Yamashita, T. Diversity of visual pigments from the viewpoint of $G$ protein activation comparison with other $\mathrm{G}$ protein-coupled receptors. Photochem. Photobiol. Sci. 2, 1237-1246 (2003).

92. Terakita, A. The opsins. Genome Biol 6 213 (2005).

93. Okano, T., Kojima, D., Fukada, Y., Shichida, Y. \& Yoshizawa, T. Primary structures of chicken cone visual pigments: vertebrate rhodopsins have evolved out of cone visual pigments. Proc. Natl Acad. Sci. USA 89. 5932-5936 (1992)

94. Kuwayama, S., Imai, H., Hirano, T., Terakita, A. \& Shichida, Y. Conserved proline residue at position 189 in cone visual pigments as a determinant of molecular properties different from rhodopsins. Biochemistry 41, 15245-15252 (2002)

95. Terakita, A. et al. Counterion displacement in the molecular evolution of the rhodopsin family. Nature Struct. Mol. Biol. 11, 284-289 (2004).

96. Imai, H. et al. Molecular properties of rod and cone visual pigments from purified chicken cone pigments to mouse rhodopsin in situ. Photochem. Photobiol. Sci. 4, 667-674 (2005)

This paper provides an excellent summary of the molecular properties that distinguish cone opsins from rhodopsin.

97. Kuwayama, S., Imai, H., Morizumi, T. \& Shichida, Y. Amino acid residues responsible for the meta-III decay rates in rod and cone visual pigments. Biochemistry 44, 2208-2215 (2005)

98. Okano, T., Yoshizawa, T. \& Fukada, Y. Pinopsin is a chicken pineal photoreceptive molecule. Nature 372 , 94-97 (1994)

99. Sun, H., Gilbert, D. J., Copeland, N. G., Jenkins, N. A \& Nathans, J. Peropsin, a novel visual pigment-like protein located in the apical microvilli of the retina pigment epithelium. Proc. Natl Acad. Sci. USA 94 9893-9898 (1997)

100. Koyanagi, M. et al. Bistable UV pigment in the lamprey pineal. Proc. Natl Acad. Sci. USA 101 6687-6691 (2004)

101. Su, C. Y. et al. Parietal-eye phototransduction components and their potential evolutionary implications. Science 311, 1617-1621 (2006).

102. Carleton, K. L., Spady, T. C. \& Cote, R. H. Rod and cone opsin families differ in spectral tuning domains but not signal transducing domains as judged by saturated evolutionary trace analysis. J. Mol. Evol. 61 , 75-89 (2005).

103. Fu, Y. B. et al. Intrinsically photosensitive retinal ganglion cells detect light with a vitamin A-based photopigment, melanopsin. Proc. Natl Acad. Sci. USA 102, 10339-10344 (2005).

104. Chaurasia, S. S. et al. Molecular cloning, localization and circadian expression of chicken melanopsin (Opn4): differential regulation of expression in pineal and retinal cell types. J. Neurochem. 92, 158-170 (2005).

105. Kumbalasiri, T. \& Provencio, I. Melanopsin and other novel mammalian opsins. Exp. Eye Res. 81, 368-375 (2005)

106. Yan, E. C. Y. et al. Retinal counterion switch in the photoactivation of the $\mathrm{G}$ protein-coupled receptor rhodopsin. Proc. Natl Acad. Sci. USA 100. 9262-9267 (2003)

107. Wang Z., Asenjo, A. B. \& Oprian, D. D. Identification of the $\mathrm{Cl}^{-}$-binding site in the human red and green color vision pigments. Biochemistry 32, 21 25-2130 (1993).

108. Hunt, D. M. et al. in Vision Down Under 2007 (Cairns, Australia, 2007)

109. von Baer, K. E. Über Entwickelungsgeschichte der Thiere (Bei den Gebrüdern Bornträger, Königsburg, 1828)

110. Haeckel, E. H. Natürliche Schöpfungsgeschichte (1868).

11. Valleix, S. et al. Homozygous nonsense mutation in the FOXE3 gene as a cause of congenital primary aphakia in humans. Am. J. Hum. Genet. 79, 358-364 (2006)

112. England, S. J., Blanchard, G. B., Mahadevan, L. \& Adams, R. J. A dynamic fate map of the forebrain shows how vertebrate eyes form and explains two causes of cyclopia. Development 133, 4613-4617 (2006).
By following the trajectories of individual identified cells, the authors of this study were able to track the morphological development of the zebrafish eye. This paper contains some excellent animations.

113. Assheton, R. On the development of the optic nerve of vertebrates, and the choroidal fissure of embryonic life. Q. J. Microsc. Sci. 34, 84-104 (1892).

114. Reichenbach, A. \& Robinson, S. R. Phylogenetic constraints on retinal organisation and development. Prog. Retin. Eye Res. 15, 139-171 (1995). This paper provides an excellent review of vertebrate eye evolution and development that, when first published, was far ahead of its time.

115. Vigh, B. et al. Nonvisual photoreceptors of the deep brain, pineal organs and retina. Histol. Histopathol. $17,555-590$ (2002)

116. Klein, D. C. Evolution of the vertebrate pineal gland: the AANAT hypothesis. Chronobiol. Int. 23, 5-20 (2006).

117. Mano, H. \& Fukada, Y. A median third eye: pineal gland retraces evolution of vertebrate photoreceptive organs. Photochem. Photobiol. 83, 11-18 (2007)

118. Turner, D. L. \& Cepko, C. L. A common progenitor for neurons and glia persists in rat retina late in development. Nature 328, 131-136 (1987).

119. Holt, C. E., Bertsch, T. W., Ellis, H. M. \& Harris, W. A. Cellular determination in the Xenopus retina is independent of lineage and birth date. Neuron 1, 15-26 (1988)

120. Wetts, R. \& Fraser, S. E. Multipotent precursors can give rise to all major cell types of the frog retina. Science 239, 1142-1145 (1988)

121. Livesey, F. J. \& Cepko, C. L. Vertebrate neural cell-fate determination: lessons from the retina. Nature Rev. Neurosci. 2, 109-118 (2001).

122. Blackshaw, S. et al. Genomic analysis of mouse retinal development. PLoS Biol. 2, 1411-1431 (2004).

123. Poggi, L., Vitorino, M., Masai, I. \& Harris, W. A. Influences on neural lineage and mode of division in the zebrafish retina in vivo. J. Cell Biol. 171, 991-999 (2005).

124. Cayouette, M., Poggi, L. \& Harris, W. A. Lineage in the vertebrate retina. Trends Neurosci. 29, 563-570 (2006).

125. Sernagor, E., Eglen, S., Harris, B. \& Wong, R. Retinal Development (Cambridge Univ. Press, Cambridge, UK 2006)

126. Johnson, P. T., Williams, R. R., Cusato, K. \& Reese, B. E. Rods and cones project to the inner plexiform layer during development. J. Comp. Neurol. 414, $1-12$ (1999).

127. Reese, B. E. Developmental plasticity of photoreceptors. Prog. Brain Res. 144, 3-19 (2004). Along with reference 126 , this paper presents evidence that, during mammalian retinal development, connections form from photoreceptors directly to the IPL, before subsequently being retracted - an important phenomenon that is widely overlooked.

128. Dăvid, C., Frank, C. L., Lukăts, A., Szél, A. \& Vĩgh, B. Cerebrospinal fluid contacting neurons in the reduced brain ventricular system of the Atlantic hagfish, Myxine glutinosa. Acta Biol. Hung. 54, 35-44 (2003).

129. García-Fernández, J. M. \& Foster, R. C. Immunocytochemical identification of photoreceptor proteins in hypothalamic cerebrospinal fluid contacting neurons of the larval lamprey (Petromyzon marinus). Cell Tissue Res. 275, 319-326 (1994).

130. Mariani, A. P. Biplexiform cells: ganglion cells of the primate retina that contact photoreceptors. Science 216, 1134-1136 (1982).

131. Straznicky, C. \& Gabriel, R. Synapses of biplexiform ganglion cells in the outer plexiform layer of the retina in Xenopus laevis. J. Brain Res. 36, 135-141 (1995)

132. Rio, J. P., Vesselkin, N. P., Repérant, J., Kenigfest, N. B. \& Versaux-Botteri, C. Lamprey ganglion cells contact photoreceptor cells. Neurosci. Lett. 250, 103-106 (1998)

133. Pushchin, I. I. \& Kondrashev, S. L. Biplexiform ganglion cells in the retina of the perciform fish Pholidapus dybowskii revealed by HRP labeling from the optic nerve and optic tectum. Vision Res. 43, 1117-1133 (2003)

134. Nilsson, D.-E. \& Pelger, S. A pessimistic estimate of the time required for an eye to evolve. Proc. Biol. Sci. 256, 53-58 (1994).

135. Delarbre, C., Gallut, C., Barriel, V., Janvier, P. $\delta$ Gachelin, G. Complete mitochondrial DNA of the hagfish, Eptatretus burgeri: the comparative analysis of mitochondrial DNA sequences strongly supports the cyclostome monophyly. Mol. Phylogenet. Evol. 22 184-192 (2002) 
136. Takezaki, N., Figueroa, F., Zaleska-Rutczynska, Z. \& Klein, J. Molecular phylogeny of early vertebrates: monophyly of the Agnathans as revealed by sequences of 35 genes. Mol. Biol. Evol. 20, 287-292 (2003).

137. Blair, J. E. \& Hedges, S. B. Molecular phylogeny and divergence times of deuterostome animals. Mol. Biol. Evol. 22, 2275-2284 (2005).

138. Kuraku, S. \& Kuratani, S. Time scale for cyclostome evolution inferred with a phylogenetic diagnosis of hagfish and lamprey cDNA sequences. Zool. Sci. 23 1053-1064 (2006).

139. Bourlat, S. J. et al. Deuterostome phylogeny reveals monophyletic chordates and the new phylum Xenoturbellida. Nature 444, 85-88 (2006)

140. Janvier, P. Evolutionary biology: born-again hagfishes. Nature 446, 622-623 (2007)

141. Janvier, P. in Major Transitions in Vertebrate Evolution (eds Anderson, J. S. \& Sues, H.-D.) 57-121 (Indiana Univ. Press, Bloomington, USA, 2007)

142. Ota, K. G., Kuraku, S. \& Kuratani, S. Hagfish embryology with reference to the evolution of the neural crest. Nature 446, 672-675 (2007). This study presented a remarkable breakthrough in the investigation of hagfish embryology that provided unequivocal evidence for neural crest cells.

143. Wagner, H. J., Frohlich, E., Negishi, K. \& Collin, S. P. The eyes of deep-sea fish II. Functional morphology of the retina. Prog. Retin. Eye Res. 17, 637-685 (1998)

144. Janvier, P. Vertebrate characters and the Cambrian vertebrates. C. R. Palevol 2, 523-531 (2003).

145. Wicht, H. \& Northcutt, R. G. Ontogeny of the head of the Pacific hagfish (Eptatretus stouti, Myxinoidea): development of the lateral line system. Philos. Trans. R. Soc. Lond. B Biol. Sci. 349, 119-134 (1995).

146. Miyata, T. \& Suga, H. Divergence pattern of animal gene families and relationship with the Cambrian explosion. Bioessays 23, 1018-1027 (2001).

147. Nakashima, Y. et al. Origin of the vertebrate visual cycle: genes encoding retinal photoisomerase and two putative visual cycle proteins are expressed in whole brain of a primitive chordate. J. Comp. Neurol. 460, 180-190 (2003)

148. Kojima, D. et al. Novel G -mediated phototransduction cascade in scallop visual cells. J. Biol. Chem. 272 , 22979-22982 (1997).

149. Walls, G. L. The Vertebrate Eye and its Adaptive Radiation (Hafner, New York, 1942).

150. Vigh, B., Vigh-Teichmann, I., Röhlich, P. \& Oksche, A. Cerebrospinal fluid-contacting neurons, sensory pinealocytes and Landolts clubs of the retina as revealed by means of an electron-microscopic immunoreaction against opsin. Cell Tissue Res. 233. 539-548 (1983)
151. McCauley, D. W. \& Bronner-Fraser, M. Conservation of Pax gene expression in ectodermal placodes of the lamprey. Gene 287, 129-139 (2002).

152. Fritzsch, B., Sonntag, R., Dubuc, R., Ohta, Y. \& Grillner, S. Organization of the six motor nuclei innervating the ocular muscles in lamprey. J. Comp. Neurol. 294, 491-506 (1990)

153. Bullock, T. H., Moore, J. K. \& Fields, R. D. Evolution of myelin sheaths: both lamprey and hagfish lack myelin. Neurosci. Lett. 48, 145-148 (1984).

154. Kolb, H. \& Famiglietti, E. V. Rod and cone pathways in inner plexiform layer of cat retina. Science $\mathbf{1 8 6}$ 47-49 (1974).

155. Wong, R. O. L., Henry, G. H. \& Medveczky, C. J. Bistratified amacrine cells in the retina of the tammar wallaby - Macropus eugenii. Exp. Brain Res. 63. 102-105 (1986).

156. Kuchnow, K. P. Elasmobranch pupillary response. Vision Res. 11, 1395-1406 (1971).

157. Sivak, J. G. \& Gilbert, P. W. Refractive and histological study of accommodation in two species of sharks (Ginglymostoma cirratum and Carcharhinus milberti). Can. J. Zool. 54, 1811-1817 (1976)

158. Sivak, J. G., Levy, B., Weber, A. P. \& Glover, R. F. Environmental influence on shape of the crystalline lens - the amphibian example. Exp. Biol. 44, 29-40 (1985).

159. Jacobs, G. H. \& Rowe, M. P. Evolution of vertebrate colour vision. Clin. Exp. Optom. 87, 206-216 (2004)

160. Conway Morris, S. The fossil record and the early evolution of the Metazoa. Nature 361, 219-225 (1993)

161. Peterson, K. J. \& Butterfield, N. J. Origin of the Eumetazoa: testing ecological predictions of molecular clocks against the Proterozoic fossi record. Proc. Natl Acad. Sci. USA 102, 9547-9552 (2005)

162. Janvier, P., Desbiens, S., Willett, J. A. \& Arsenault, M. Lamprey-like gills in a gnathostome-related Devonian jawless vertebrate. Nature 440, 1183-1185 (2006).

163. Botella, H., Blom, H., Dorka, M., Ahlberg, P. E. \& Janvier, P. Jaws and teeth of the earliest bony fishes. Nature 448, 583-586 (2007).

164. Stadler, P. F. et al. Evidence for independent Hox gene duplications in the hagfish lineage: a PCR-based gene inventory of Eptatretus stoutii. Mol. Phylogenet. Evol. 32, 686-694 (2004).

165. Houseman, J. External features of the anterior region of amphioxus, the lancelet. BIODIDAC [online], http:// biodidac.bio.uottawa.ca/thumbnails/filedet.htm?File name $=$ CEPL037P\&File type $=$ GIF

166. McGrouther, M. Head of a broadgilled hagfish. Australian Museum [online] http://www.austmus. gov. au/fishes/fishfacts/fish/ecirrhatus4.htm (2006).
167 Collin S. P \& Trezise, A. E. O in Communication in Fishes (eds Ladich, F., Collin, S. P., Moller, P. \& Kapoor, B. G.) 303-335 (Science Publishers, 2006).

168. Steinberg, R. H., Fisher, S. K. \& Anderson, D. H. Disk morphogenesis in vertebrate photoreceptors. J. Comp. Neurol. 190, 501-518 (1980).

169. Vigh, B., Debreceni, K., Fejer, Z. \& Vigh-Teichmann, I. Immunoreactive excitatory amino acids in the parietal eye of lizards, a comparison with the pineal organ and retina. Cell Tissue Res. 287, 275-283 (1997).

170. Raviola, E\& Gilula, N. B. Intramembrane organization of specialized contacts in outer plexiform layer of retina - a freeze-fracture study in monkeys and rabbits. J. Cell Biol. 65, 192-222 (1975).

171. Hardie, R. C. \& Raghu, P. Visual transduction in Drosophila. Nature 413, 186-193 (2001).

172. Burns, M. E. \& Lamb, T. D. in The Visual Neurosciences (eds Chalupa, L. M. \& Werner, J. S.) 215-233 (MIT Press, Cambridge, Massachusetts, 2003).

173. Dreher, B. \& Robinson, S. R. Development of the retinofugal pathway in birds and mammals: evidence for a common 'timetable'. Brain Behav. Evol. 31, 369-390 (1988)

174. Johnson, P. T., Raven, M. A. \& Reese, B. E. Disruption of transient photoreceptor targeting within the inner plexiform layer following early ablation of cholinergic amacrine cells in the ferret. Vis. Neurosci. 18, 741-751 (2001).

\section{Acknowledgements}

We wish to thank T. Cronin, I. Meinertzhagen, S. Conway Morris and P. Janvier for constructive comments on the manuscript. This work was supported by the Australian Research Council (FF0344672; T.D.L. and S.P.C.) and by the US National Institutes of Health and the Research to Prevent Blindness Foundation (E.N.P.)

DATABASES

Entrez Gene: http://www.ncbi.nlm.nih.gov/entrez/query. fcgi?db=gene

Ci-Opsin1 $|P A X 6|$ RAX $\mid$

OMIM: http://www.ncbi.nlm.nih.gov/entrez/query.

fcgi?db=OMIM

congenital primary aphakia

UniProtKB: http://ca.expasy.org/sprot

FURTHER INFORMATION

Trevor D. Lamb's homepage: http://jcsmr.anu.edu.au/org/

dns/visual/index.php

SUPPLEMENTARY INFORMATION

See online article: $\underline{S 1 \text { (animation) }}$

ALL LINKS ARE ACTIVE IN THE ONLINE PDF 